\title{
Loxoscelism: Advances and Challenges in the Design of Antibody Fragments with Therapeutic Potential
}

\author{
Sabrina Karim-Silva ${ }^{1}$, Alessandra Becker-Finco ${ }^{1}$, Isabella Gizzi Jiacomini ${ }^{1,2}{ }^{\mathbb{D}}$, Fanny Boursin ${ }^{2}$, \\ Arnaud Leroy ${ }^{3}$, Magali Noiray ${ }^{3}$, Juliana de Moura ${ }^{1}$, Nicolas Aubrey ${ }^{2}$, Philippe Billiald ${ }^{3,4, *(D)}$ \\ and Larissa M. Alvarenga ${ }^{1, *}$ \\ 1 Laboratório de Imunoquímica, Departamento de Patologia Básica, Universidade Federal do Paraná, \\ Curitiba CEP 81531-980 PR, Brazil; sabrinaimtair@yahoo.com.br (S.K.-S.); abeckerfinco@gmail.com (A.B.-F.); \\ bella.jiacomini@gmail.com (I.G.J.); julianademoura@ufpr.br (J.d.M.) \\ 2 INRA, UMR 1282, Faculté de Pharmacie, Université de Tours, 37200 Tours, France; \\ fanny.boursin@univ-tours.fr (F.B.); nicolas.aubrey@univ-tours.fr (N.A.) \\ 3 IPSIT (Chiral-ist), School of Pharmacy, University Paris-Saclay, 92296 Châtenay-Malabry, France; \\ leroy.arnau@wanadoo.fr (A.L.); magali.noiray@universite-paris-saclay.fr (M.N.) \\ 4 MCAM, UMR MNHN-CNRS 7245, Muséum national d'Histoire naturelle, 75231 Paris, France \\ * Correspondence: philippe.billiald@universite-paris-saclay.fr (P.B.); lmalvarenga@gmail.com (L.M.A.)
}

Received: 20 March 2020; Accepted: 13 April 2020; Published: 16 April 2020

\begin{abstract}
Envenoming due to Loxosceles spider bites still remains a neglected disease of particular medical concern in the Americas. To date, there is no consensus for the treatment of envenomed patients, yet horse polyclonal antivenoms are usually infused to patients with identified severe medical conditions. It is widely known that venom proteins in the 30-35 kDa range with sphingomyelinase $\mathrm{D}$ (SMasesD) activity, reproduce most of the toxic effects observed in loxoscelism. Hence, we believe that monoclonal antibody fragments targeting such toxins might pose an alternative safe and effective treatment. In the present study, starting from the monoclonal antibody LimAb7, previously shown to target SMasesD from the venom of L. intermedia and neutralize its dermonecrotic activity, we designed humanized antibody V-domains, then produced and purified as recombinant single-chain antibody fragments (scFvs). These molecules were characterized in terms of humanness, structural stability, antigen-binding activity, and venom-neutralizing potential. Throughout this process, we identified some blocking points that can impact the Abs antigen-binding activity and neutralizing capacity. In silico analysis of the antigen/antibody amino acid interactions also contributed to a better understanding of the antibody's neutralization mechanism and led to reformatting the humanized antibody fragment which, ultimately, recovered the functional characteristics for efficient in vitro venom neutralization.
\end{abstract}

Keywords: venom; antivenom; neutralization; loxosceles; sphingomyelinase D; humanization; scFv

Key Contribution: The humanization of a mouse antibody V-domains able to neutralize Loxosceles intermedia venom paves the way for a new generation of anti-venom therapy. This study highlights the importance of understanding the antibody's mechanism of neutralization for appropriate design of innovative antidotes. Likewise, preserving favorable physico-chemical properties and antigen-binding activity is a challenge yet to be further addressed when considering pre-clinical trials.

\section{Introduction}

To date the Loxosceles genus is comprised of 139 described spider species, differentially distributed and found in all five continents where different species have been reported [1]. In Brazil, L. intermedia, 
L. gaucho, and L. laeta are of particular medical concern, as in 2019 the number of reported envenomations was 8490, of which 11 were fatal for humans [2,3]. The diagnosis for loxoscelism is often impaired and belatedly given as bites are usually painless and often go unnoticed, including clinical manifestations that appear only several hours afterwards. Symptoms start two to eight hours post-event and are marked by an intense inflammatory reaction at the bite site, followed by local necrosis that can lead to ulcers of variable sizes. Such lesions often heal within 6 to 8 weeks, but can leave lasting scars which may even require surgical excision [4]. Viscerocutaneous, also designated as systemic loxoscelism, is the most serious clinical manifestation and accounts for up to $27 \%$ of cases [5]. It is characterized by fever, nausea, hematuria, hemoglobinuria, and disseminated intravascular coagulation. Occasionally, extensive hemolysis may lead to acute kidney injury and renal failure, the primary cause of loxoscelism-associated deaths.

Usually, bites result in the intradermal injection of few microliters of venom corresponding to around 50 micrograms of protein. As indicated by 2D electrophoresis, the protein content of the venom has great interspecies similarity, with proteins ranging from 2 to $94 \mathrm{kDa}$. This includes serine proteases, serine protease inhibitors, hyaluronidases, inhibitor cystine knot (ICK) peptides and phospholipases D (PLD), the latter being the most studied and well-characterized venom components due to their ability to induce dermonecrotic lesions and hemolysis [6]. More than 25 spots immunologically related to PLD toxins have been identified in the L. intermedia venom, most of them being SMase D-related [7]. A great number of studies has been carried out on these toxins. Nine isoforms of PLDs have been recombinantly produced and expressed as soluble and active enzymes that reproduce most of the toxic effects observed in loxoscelism [8-12]. X-ray crystallography analysis of recombinant LiRecDT1 SMase D (SMase D LiRecDT1) from L. intermedia, both wild-type and H12A-mutant forms, are available and the catalytic pocket of the enzyme is well-identified [13]. This and other reports reveal important insights into the enzymatic properties of each one of the isoforms, but also underline clear differences in the hydrolytic ability of PLD isoforms within the Loxosceles genus.

To date, there is no consensus treatment for the management of patients who are admitted to the hospital 12 to $24 \mathrm{~h}$ after the bite [14,15]. Symptomatic and non-specific treatments have been implemented in most countries for the treatment of the less critical cases. In South America, horse polyclonal antivenoms are available and usually infused intravenously to all patients showing viscerocutaneous loxoscelism. These preparations are mostly comprised of $\mathrm{F}(\mathrm{ab})^{\prime}{ }_{2}$, but also whole IgGs (Peru) [14-16]. They target all the components of the venom and may neutralize toxins by various mechanisms, including direct inhibition of the toxin's catalytic site, steric hindrance, and allosteric inhibition. However, these Loxosceles antivenoms have often been less successful than those produced for the treatment of snake envenomings, in light of their effectiveness [15]. There is no direct relationship between toxicity of the venom's molecules and their immunogenicity, and antibodies raised against Loxosceles dermonecrotic toxins often show low interspecies cross-reactivity $[17,18]$. In addition, such conventional antivenoms based on animal immunization belong to the category of blood-based products as defined by the regulatory authorities, with safety concerns, not chemically well-defined components, and high batch to batch variability. Polyclonal antibodies present limited specific activity, thus they might bind to toxin components, but not necessarily neutralize them and could be effectively substituted with specific anti-SMase D antibodies [19]. In this context, recombinant binding-proteins with toxin neutralization potential could be an interesting alternative.

One promising and suitable strategy for whole venom neutralization consists in using monoclonal or oligoclonal antibody fragments. Several antibodies discovered against Loxosceles venom components have been previously generated $[17,20,21]$. However, only one (LimAb7) satisfies all the criteria required in terms of specificity, affinity, and neutralizing capacity [20]. LimAb7 specifically binds to 32-35 kDa components of L. intermedia venom and is reactive to the SMase D LiRecDT1 toxin. This antibody was also shown to neutralize the venom's dermonecrotic activity in rabbits, while recombinant antibody fragments preserved antigen-binding affinity and the ability to neutralize the venom in vitro [22]. Nonetheless, the potential immunogenicity of antibodies from mouse origin is a major 
barrier to infusion in humans. This drawback can be overcome by modifications on the framework regions of the antibody's V-domains, through a process termed antibody humanization, which reduces its immunogenic potential while maintaining the bioactivity of the antibody molecule $[23,24]$. All things considered, we hereby designed and evaluated a recombinant humanized antibody fragment constructed from LimAb7 complementarity determining regions (CDRs). During this process, we clearly identified some blocking points that could impact in the antibody's antigen-binding activity, neutralizing capacity, and pharmaceutical development. In silico mapping of the antigen/antibody interaction also contributed to a better understanding of its intrinsic neutralization mechanism and has led us to reformat the humanized antibody fragment which, ultimately, recovered the functional characteristics required for efficient in vitro neutralization of the venom.

\section{Results}

\subsection{Design of a Humanized scFv Anti- L. Intermedia Venom}

Structural analysis of LimAb7 allowed us to identify all three CDRs of each V-domain (Figure 1). Length-independent canonical class and sub-class for the non-H3 CDRs were identified as L1-similar to 3/17A; L2-1/7A; L3-similar to 5/11A; H1- similar to 1/10A; H2-2/10A. The packing angle of VH and VL domains, influential to the topography of the antigen-combining site, was predicted to be -42.8 [25]. The humanness score of the V-domain sequences $(-1.132$ and -1.164 for VH and VL, respectively) clearly indicated a high risk of immunogenicity, all parameters being accounted for further humanization [26].

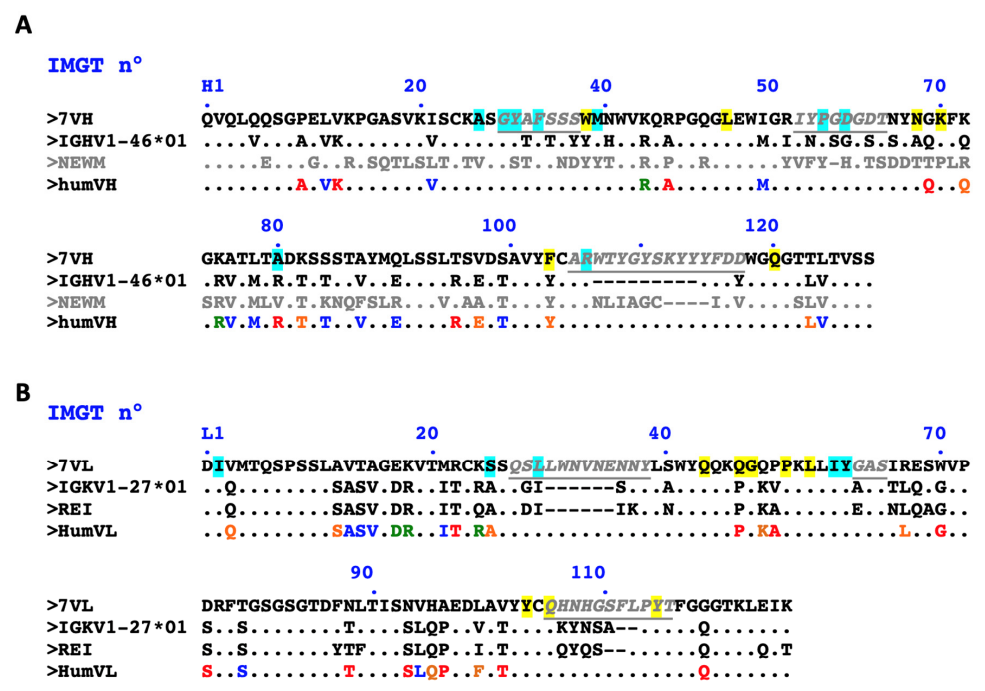

Figure 1. Design of humanized LimAb7 V-domains. (A) Sequence alignment of the mouse LimAb7 IGHV (7VH) with human germline sequence IGHV1-46*01, the NEWM protein sequence ("fixed framework" strategy) and the humanized LimAb7 IGHV (humVH) that retains antigen-binding activity. (B) Sequence alignment of the mouse LimAb7 IGKV (7VL) with human germline sequence IGKV1-27*01, the REI protein sequence ("fixed framework" strategy) and the humanized LimAb7 IGKV (humVL) that retains antigen-binding activity. CDRs according to IMGT are in italic, underlined, grey. Residues at key sites for canonical structures are highlighted in light blue. Residues buried in $\mathrm{VH} / \mathrm{VL}$ interfaces are highlighted in yellow. Based on the physico-chemical classes of the amino acids (AA), differences in the framework regions of mouse LimAb7 and its humanized variants are classified into very similar AA (green), similar AA (blue), dissimilar AA (orange) and very dissimilar AA (red).

Sequence database searches allowed us to identify human germline genes closely related to LimAb7 V-domains (IGHV and IGKV) and perform an alignment of the deduced AA residues sequences. We also aligned the LimAb 7 sequences with NEWM (PDB: 7FAB) and REI (PDB: 1REI) myeloma antibody sequences for VH and VL, respectively. These sequences are often used in a "fixed framework" 
strategy for antibody humanization [24]. However, NEWM was dropped of this study due to its substantial sequence dissimilarity with IGHV-LimAb7 ( $<50 \%$ identity), whilst the human germline IGKV sequence (IGKV1-27*01) was identified as one of the most similar human template for the kappa chain $(60.0 \%$ identity).

For each of the LimAb7 V-domains, 29 AA residues differed from the human acceptor frameworks (FR). We paid close attention to maintaining cohesion between most residues at positions in VL and $\mathrm{VH}$ buried in the interface between the domains. In order to create and secure a PpL binding site that is highly dependent on several residues belonging to IGKV FR1 and residues L90 and L127 as well, the whole FR1 of REI protein was introduced while maintaining residues T (L90) and K (L127) [27]. All throughout the process, the modifications were approved after detailed analysis in order to confirm the ongoing improvement of the humanness Z-score and the decrease of the residual immunogenicity (Figure 2). Canonical class and sub-class CDRs were preserved for L1, L2, L3 and H1 while high similarity with canonical class 2/10A was maintained for $\mathrm{H} 2$ (residue H80: preferentially Arg but also Val). The expected VH/VL packing angle was slightly modified upon the process ( -42.8 for LimAb7 and -45.4 for the humanized version) but this change was considered acceptable. Lastly, 23 and 26 residues were mutated for IGHV and IGKV, respectively. A 3D structural model of the humanized $\mathrm{V}$-domains of LimAb7 is shown in Figure 2C.

A

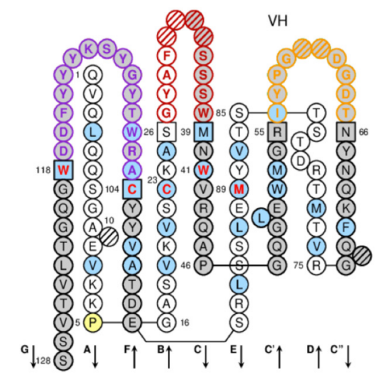

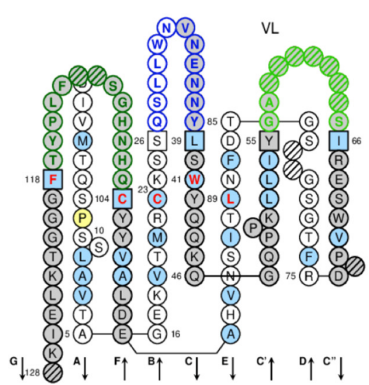

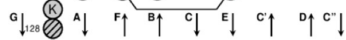

B

Sequence identity (\%) with closest human germline and the humanness Z-score [--]

\begin{tabular}{|llllllr|}
\hline & \multicolumn{2}{c}{ V-domain } & \multicolumn{3}{c|}{ Individual humanized FR region } \\
& Mouse & Humanized & FR1 & FR2 & FR3 \\
\hline IGHV & $67.3[-1.132]$ & $86.7[-0.080]$ & 96 & 100 & 95 \\
IGkV & $71[-1.644]$ & $84.2[0.232]$ & 100 & 100 & 100 \\
\hline
\end{tabular}

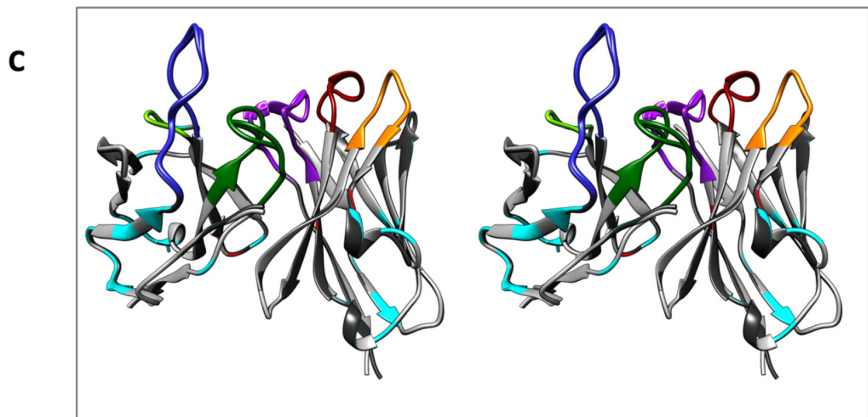

Figure 2. LimAb7 humanized V-domains. (A) Secondary structure representation of the variable region sequences in the "collier de perles" format with coloured CDRs (H1: red, H2: orange; H3: purple; L1: blue; L2: light blue; L3: forest green). Arrows indicate $\beta$-strands. (B) Comparative analysis between the LimAb7 antibody mouse variable region sequences and the modified sequences after humanization with human germline sequences. Percentage of sequence identity with the closest human germline considering the whole V-domain sequence or each individual humanized FR. The humanness Z-score of each domain is also indicated into brackets. (C) Stereo view of $\mathrm{scFv}_{15} \mathrm{hLi7}$. Mutated residues exposed at the surface are in cyan. Residues buried in VH/VL interfaces and mutated upon humanization are in red. 


\subsection{Primary Screening of $s c F v_{15} h \mathrm{Li} 7$}

A synthetic codon-optimized bacterial gene encoding the monomeric single-chain antibody fragment $\mathrm{scFv}_{15} \mathrm{hLi7}$ made up from the humanized $\mathrm{VH}$ domain of LimAb7 fused to the humanized VL domain via a flexible 15 residues linker was designed (Figure 3A). Pilot expression was carried in the periplasm of bacteria and the recombinant antibody fragment was isolated from other periplasmic proteins by affinity chromatography using PpL-affinity resin (Figure 3B). No precipitation was observed in the elution peak after neutralization and buffer exchange to PBS pH 7.2. A samples' electrophoretic profile analysis confirmed the identity of the purified protein which appeared as a unique $29 \mathrm{kDa}$ protein after Coomassie Blue staining, as well as after Western blotting using the PpL-peroxidase conjugate under non-reducing conditions. Dot blot allowed a rapid screening to validate the ability of $\mathrm{scFv}_{15} \mathrm{hLi} 7$ to bind L. intermedia venom in a specific manner with no detectable cross-reactivity with L. laeta and L. gaucho venoms (Figure 3C).

A

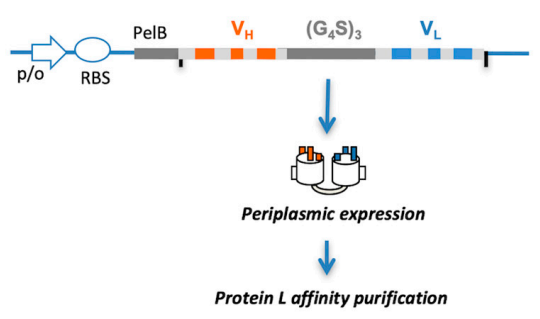

D

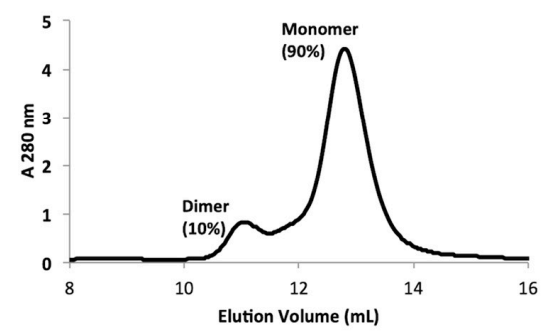

B

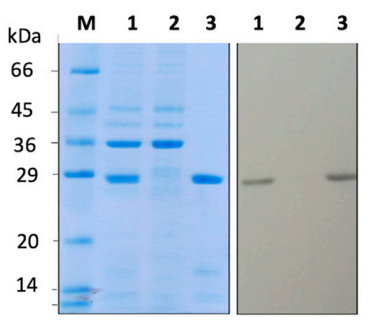

B1

E

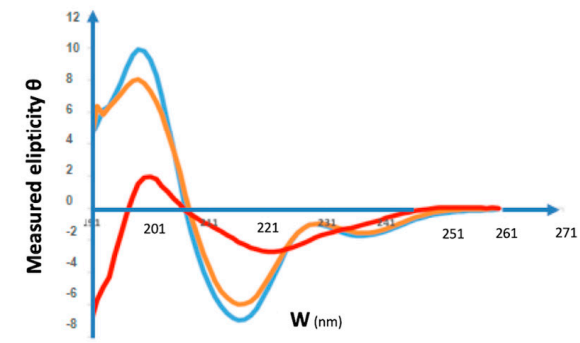

Figure 3. Design, expression and purification of $\mathrm{scFv}_{15} \mathrm{hLi7}$. (A) Schematic representation of the design and expression cassette. The open reading frame is under the control of a T7 promoter and contains a PelB signal sequence for periplasmic expression followed by a cDNA encoding humanized $\mathrm{VH}$ and $\mathrm{VL}$ fused together via a $\left(\mathrm{Gly}_{4} \mathrm{Ser}\right)_{3}$ linker. This allows expression of monomeric untagged $\mathrm{scFv}_{15} \mathrm{hLi}$. (B) Protein expression $\mathrm{scFv}_{15} \mathrm{hLi} 7$ analysis in periplasmic extract by polyacrylamide gel electrophoresis (SDS-PAGE) and Western blot, before and after affinity purification. B1, 12.5\% SDS-PAGE gel under non reducing conditions stained with Coomassie blue. The numbers correspond to PpL affinity chromatography column fractions (1) crude periplasmic extract; (2) column flow-through fraction, containing many of the bacterial proteins observed in the crude periplasmic extract; (3) proteins eluted by an acid solution pH 2.8. (M) Molecular weight marker (Sigma M3913). B2, nitrocellulose membrane for Western blot analysis developed with PpL-peroxidase conjugate. (C) Dot blot analysis of the periplasmic extract containing recombinant $\mathrm{scFv}_{15} \mathrm{hLi7}$. L. intermedia ( $\left.\mathrm{Li}\right)$, L. gaucho $(\mathrm{Lg})$, and L. laeta (Ll) venoms $(2.5 \mu \mathrm{g})$ spotted onto nitrocellulose membrane. $\mathbf{C 1}$, Confirmation of venom's presence in the membrane by Ponceau reversible staining. $\mathbf{C}$, nitrocellulose membrane incubated with periplasmic extract containing recombinant scFv15hLi7, developed with PpL-peroxidase. (D) Size-exclusion chromatography of the PpL-purified scFv15hLi7 using a calibrated Superdex 75 10/300GL column. (E) Far UV-CD analysis of the PpL-purified scFv15hLi7 at $20^{\circ} \mathrm{C}$ (blue), $40^{\circ} \mathrm{C}$ (orange) and $50{ }^{\circ} \mathrm{C}$ (red). 


\subsection{Physico-Chemical Characterization and Stability Analysis of $s c F v_{15} h L i 7$}

Based on the observations stated above, PpL-purified $\mathrm{scFv}_{15} \mathrm{hLi} 7$ was produced at a larger scale at Genscript (Piscataway, NJ, USA) and used for further characterization. SDS-PAGE and Western blotting confirmed correct production and PpL-purification of the recombinant protein. The UV-Vis spectra of the PpL-purified $\mathrm{scFv}_{15} \mathrm{hLi7}$ was monitored to detect the presence of submicron-sized aggregates. The shape of the spectra was in conformity with that of a soluble protein and confirmed that no significant aggregation/precipitation phenomenon occurred. The value recorded at $320 \mathrm{~nm}$ which reflects the scattering of light by large aggregates present in the sample was very low as compared to the value recorded at $280 \mathrm{~nm}$, the ratio $\mathrm{A}_{320 \mathrm{~nm}} / \mathrm{A}_{280 \mathrm{~nm}}$ being $2.5 \%$.

PpL-purified $\mathrm{scFv}_{15} \mathrm{hLi7}$ was analysed after SE-HPLC in order to confirm purity and for the detection of nanoaggregates and/or degradation products of the scFv in solution (Figure 3D). Two peaks of elution were observed. The smaller peak eluted at a volume $\sim 11 \mathrm{~mL}$ corresponded to proteins exhibiting an apparent $\mathrm{Mr}$ of $40-50 \mathrm{kDa}$ whereas the major peak, accounting for $90 \%$ of the total protein amount, eluted at $\sim 13 \mathrm{~mL}$, corresponding to proteins with an apparent $\mathrm{Mr}$ of $25-30 \mathrm{kDa}$. Based on that apparent $\mathrm{Mr}$, the first peak was expected to be a dimeric form of the scFv related to either a misfolding occurring during the expression or an aggregation phenomenon during the purification process, such as elution in acidic condition. The second peak was likely to be the monomeric form of $\mathrm{scFv}_{15} \mathrm{hLi7}$.

We also used circular dichroism spectroscopy as a tool to monitor structural stability of scFv ${ }_{15} \mathrm{hLi} 7$ (Figure 3E). We did not observe any major changes at temperatures beneath $35^{\circ} \mathrm{C}$. At $40^{\circ} \mathrm{C}$, a decrease of the ellipticity at $200 \mathrm{~nm}$ was observed and the ellipticity continued to decrease at $50{ }^{\circ} \mathrm{C}$ and $60{ }^{\circ} \mathrm{C}$ with a concomitant increase of the ellipticity at $218 \mathrm{~nm}$, in the same range of temperature. The shape of the $\mathrm{CD}$ spectrum of $\mathrm{scFv}_{15} \mathrm{hLi7}$ solutions at temperature under $35^{\circ} \mathrm{C}$ showed features of a $\beta$-sheet-enriched structure, with a minimum at $218 \mathrm{~nm}$ and a maximum at $\sim 201 \mathrm{~nm}$, typical of antibody-like structures. As temperature increases above $35^{\circ} \mathrm{C}$, the $\mathrm{CD}$ spectra of $\mathrm{scFv}_{15} \mathrm{hLi} 7$ displayed no isodichroic point. As a result, the folding of $\mathrm{scFv}_{15} \mathrm{hLi7}$ cannot be described by a two-state equilibrium, revealing the multidomain nature of the $\mathrm{scFv}_{15} \mathrm{hLi7}$ fragment. At temperatures above $35^{\circ} \mathrm{C}$, the protein structure of $\mathrm{scFv}_{15} \mathrm{hLi} 7$ is unstable and likely unfolded. Other than $\mathrm{CD}$ spectroscopy, we carried out a nano-differential scanning fluorimetry (nano-DSF) analysis. In using a $10 \mu \mathrm{M}$ solution of PpL-purified $\mathrm{scFv}_{15} \mathrm{hLi7}$, we observed a melting temperature $\left(\mathrm{T}_{\mathrm{M}}\right)$ of $42.2^{\circ} \mathrm{C}$ with an onset temperature of denaturation of $37.0^{\circ} \mathrm{C}$ and an onset temperature of aggregation of $41.8^{\circ} \mathrm{C}$.

\section{4. $s c F v_{15}$ hLi7 Antigen-Binding Characterization}

The recognition profile and specificity of the $\mathrm{scFv}_{15} \mathrm{hLi7}$ against Loxosceles venoms and recombinant SMase D LiD1 toxin was identified after the electrophoretic migration of the venom components followed by a nitrocellulose membrane transfer of these proteins and evaluation of the antibody-fragment binding capacity as compared to the parental mouse IgG. When $\mathrm{scFv}_{15} \mathrm{hLi} 7$ was assessed against the venom of different Loxosceles species, only the L. intermedia venom led to a recognition profile of two bands in the 32-35 $\mathrm{kDa}$ molar range, suggesting that the epitope recognized by this fragment is shared by several SMase D isoforms only pertaining to L. intermedia (Figure 4A).

Binding affinity of PpL-purified $\mathrm{scFv}_{15} \mathrm{hLi7}$ and kinetics for binding to immobilized LiD1 were analyzed in real time (Figure 4B). According to SE-HPLC analysis, the heterogeneous analyte model, which consists of two populations of molecules capable to bind to the immobilized target independently, was used. The kinetic constants measured for the monomeric $\mathrm{scFv}_{15} \mathrm{hLi7}$ representing $90 \%$ of the antibody population were $\mathrm{k}_{\mathrm{a}}=18.2 \times 10^{4} \mathrm{M}^{-1} \mathrm{~s}^{-1}, \mathrm{k}_{\mathrm{d}}=103 \times 10^{-4} \mathrm{~s}^{-1}$ resulting in a dissociation constant $\mathrm{K}_{\mathrm{D}}=56.6 \mathrm{nM}$. Under similar experimental conditions, mouse dimeric scFv 5 Li7 and IgG LimAb7 were previously shown to have significant better kinetic characteristics with a $K_{D}$ of $0.98 \mathrm{nM}$ and $0.085 \mathrm{nM}$, respectively [22]. 
A $A 1$

A3

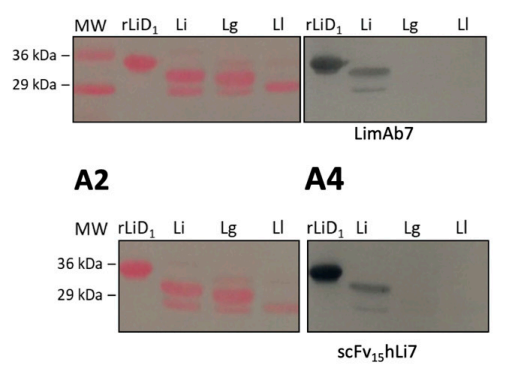

C

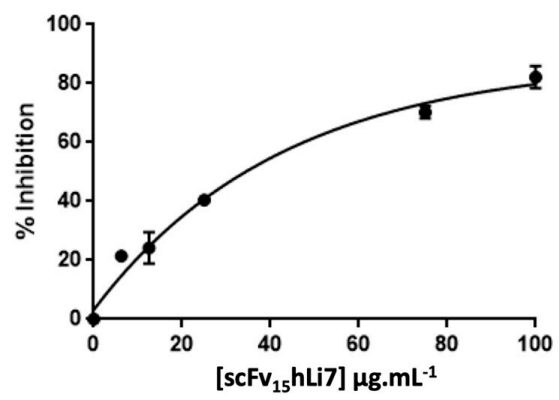

B

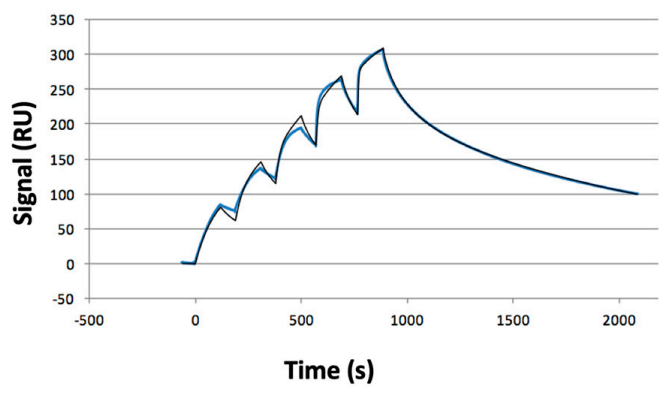

D

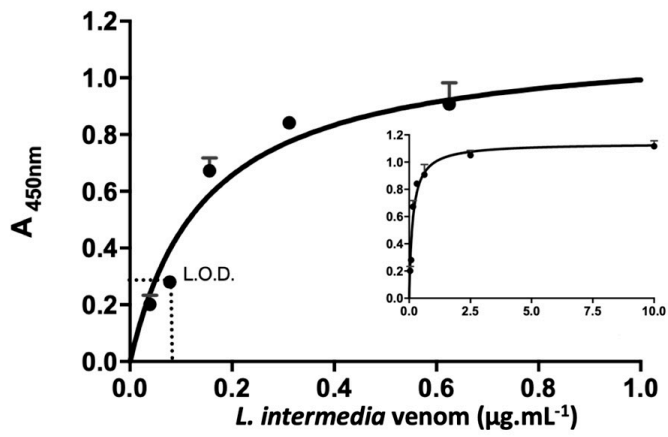

Figure 4. Functional characterization of PpL-purified $\mathrm{scFv}_{15} \mathrm{hLi7}$. (A) Western blot analysis of the $\mathrm{LimAb7}$ and periplasmic extract containing recombinant $\mathrm{scFv}_{15} \mathrm{hLi7}$. L. intermedia (Li), L. laeta (Ll) and L. gaucho $(\mathrm{Lg})(10 \mu \mathrm{g}$ of each venom) or SMase D LiD1 (rLiD1) $(10 \mu \mathrm{g})$ were resolved in a 15\% polyacrylamide gel by SDS-PAGE under non-reducing conditions and transferred to a nitrocellulose membrane A1-A2, Confirmation of venom's presence in the membrane by Ponceau reversible staining. A3, membrane incubated with $\operatorname{LimAb7}\left(20 \mu \mathrm{g} \cdot \mathrm{mL}^{-1}\right)$ and developed with peroxidase-conjugated rabbit anti-mouse IgG. A4, membrane incubated with periplasmic extract containing recombinant scFvLi ${ }_{15} \mathrm{hLi} 7$ and developed with peroxidase-conjugated PpL. (B) Interaction of immobilized rLiD1 (black line) with increasing concentration of PpL-purified $\mathrm{scFv}_{15} \mathrm{hLi7}(0.125 ; 0.25 ; 0.5 ; 1.0 ; 2.0 \mu \mathrm{M})$ analyzed by surface plasmon resonance (SPR) (Biacore 100 and fitting (blue line) with heterogeneous analyte model, monomer 90\%, dimer 10\%). (C) Competitive ELISA: immobilized L. intermedia $\left(10 \mu \mathrm{g} \cdot \mathrm{mL}^{-1}\right)$ and added $1 \mu \mathrm{g} \cdot \mathrm{mL}^{-1}$ of LimAb7 with increasing amounts of scFv ${ }_{15} \mathrm{hLi7}$. Immunocomplexes were revealed using peroxidase-conjugated anti-mouse Fc antibodies. (D) Sandwich ELISA: immobilized horse anti-L. intermedia venom $\mathrm{F}(\mathrm{ab})_{2}{ }_{2}\left(10 \mu \mathrm{g} \cdot \mathrm{mL}^{-1}\right)$ and captured L. intermedia venom gradient. $20 \mu \mathrm{g} \cdot \mathrm{mL}^{-1}$ of $\mathrm{scFv}_{15} \mathrm{hLi7}$ were added. Immunocomplexes were revealed using peroxidase-conjugated PpL. The inserted graph is the same graph with smaller $x$-axis scale.

The competitive ELISA assay also allowed us to evidence the ability of $\mathrm{scFv}_{15} \mathrm{hLi7}$ to compete with the parental IgG LimAb7 in a dose-dependent fashion. Figure 4C shows the inhibition profile in the presence of the recombinant antibody fragment. Higher concentrations of the fragment have shown to inhibit the binding of the parental $\operatorname{IgG}$ to the venom components and thereby result in a decrease in reactivity. It was estimated that about $38 \mu \mathrm{g} \cdot \mathrm{mL}^{-1}$ of scFv${ }_{15} \mathrm{hLi} 7$ is required to inhibit $50 \%$ of LimAb7 binding. A sandwich ELISA confirmed the ability of $\mathrm{scFv}_{15} \mathrm{hLi7}$ to bind to toxins of the L. intermedia venom in a dose-dependent and saturable manner with a lower limit of detection of up to $78 \mathrm{ng} \cdot \mathrm{mL}^{-1}$ of soluble toxin (Figure $4 \mathrm{D}$ ). Following this functional characterization, we moved to the evaluation of $\mathrm{scFv}_{15} \mathrm{hLi7}$ 's ability to neutralize the hemolytic activity of L. intermedia venom. Unfortunately, we couldn't observe any neutralization, whatever the experimental conditions were (data not shown). This result led us to reconsider the design of the humanized antibody fragment. 


\subsection{Modelling and Docking of LimAb7, scFv ${ }_{15}$ hLi7 with LiRecDT1}

In order to better understand LimAb7's neutralization mechanism, we proceeded to the modeling of LimAb7 and $\mathrm{scFv}_{15} \mathrm{hLi7} \mathrm{V}$-domains structures prior to in silico docking prediction with putative target SMase D LiRecDT1 (PDB: 3RLH). The molecular docking between LimAb7, scFv 15 hLi7 and their molecular target (PDB: 3RLH) was then performed and the lowest energy score interactions between the antibodies VH/VL and LiRecDT1 are represented in Figure 5. The docking analysis shows LimAb7 VH and VL CDR interactions in accordance with (D233, K234, R235, Y253). Contacts between LimAb7, $\mathrm{scFv}_{15} \mathrm{hLi7}$ and regions of SMase D LiRecDT1 (K58, K59) (D21, E22, D25), respectively, that have been indicated as highly immunogenic and targets of neutralizing anti-LiRecDT1 antibodies, residues 58-72 (CYGSKKYENFNDFLKGLR) and residues 25-51 (NLGANSIETDVSFDDNANPEYTYHGIP) were also identified. Moreover, contacts between LimAb7 and amino acids G54 and R55 were detected, some of the residues that have been previously indicated as being important for the stabilization of the catalytic loop and substrate interaction are conserved between SMase D LiRecDT1 and SMase LiDI [28,29]. The docking analysis for the $\mathrm{scFv}_{15} \mathrm{hLi7/SMase} \mathrm{D} \mathrm{LiRecDT1}$ still shows contacts in the same regions as the murine antibody (LimAb7), however some contacts with substrate-binding relevant amino acids are lost (D233, G54). Furthermore, new contacts have been observed including residues D21, E22, N25, D255 suggesting a displacement in the site of interaction when compared to LimAb7 (Table S1).

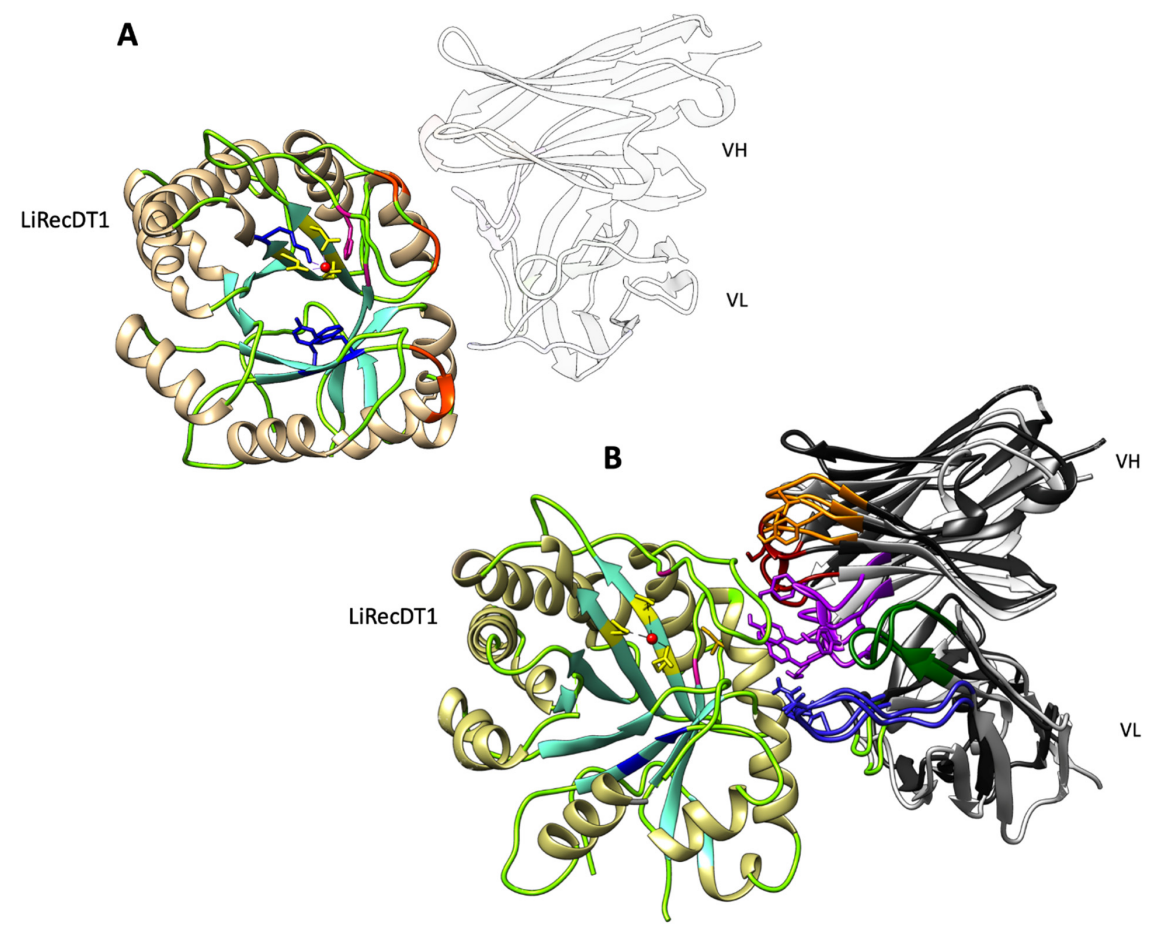

Figure 5. Docking of LimAb7, $\mathrm{scFv}_{15} \mathrm{hLi7}$ with LidRecDT1. (A) Docking results showing antibodies binding sites on the surface of SMase D (LiRecDT1, PDB: 3RLH). Ribbon representations of antibody-Lid1 interactions where the residues proposed to be involved in catalysis (H12A, H47A) are coloured in magenta, magnesium-ion binding (E32A, D34A, D91A) in yellow and substrate recognition (K93A, Y228A, and W230A) are coloured in blue; the amino acid compounds in the predicted epitope for Limab7 are represented in orange. (B) Superimposition of the best scoring docking models for LimAb7 and $\mathrm{scFv}_{15} \mathrm{hLi7}$. The VL and VH CDRs are coloured according to the IMGT colour scheme and the framework regions in black for LimAb7 and grey for $\mathrm{scFv}_{15} \mathrm{hLi7}$.

\subsection{Re-Design of Humanized scFv anti- L. Intermedia Venom}

Considering that the catalytic pocket of SMase D LiRecDT1 and LimAb7 epitope do not overlap according to docking analysis, and also that the humanization process slightly altered 
the antigen-antibody interaction, we decided to re-design the humanized antibody fragment as follows. First, we introduced two back mutations (F $103>$ Y in IGHV and P $46>$ Q in IGKV according to IMGT numbering) in the sequence of the humanized antibody fragment. We anticipated that these back mutations should restore the original VH/VL packing angle $(-42.8)$, the original topography of the antigen-binding site and possibly the structural stability of the paratope. Secondly, we produced this new version of humanized antibody in two formats: a monomeric scFv also designated scFv ${ }_{15} \mathrm{hLi7m}$ $(25 \mathrm{kDa})$ and a larger dimeric $\mathrm{scFv}_{5} \mathrm{hLi} 7 \mathrm{~m}(50 \mathrm{kDa})$ (Figure 6). For both recombinant proteins, the yield of production after PpL capture from the periplasm of induced HB2151 bacteria was higher than $1 \mathrm{mg} \cdot \mathrm{L}^{-1}$ of culture under standard conditions of culture and induction $\left(2.4 \mathrm{mg} \cdot \mathrm{L}^{-1}\right.$ and $1.2 \mathrm{mg} \cdot \mathrm{L}^{-1}$ for $\mathrm{scFv}_{15} \mathrm{hLi7m}$ and $\mathrm{scFv}_{5} \mathrm{hLi7m}$, respectively). In both cases, we did not observe any tendency to aggregation, precipitation or proteolyis as indicated by the low $\mathrm{A}_{320 \mathrm{~nm}} / \mathrm{A}_{280 \mathrm{~nm}}$ ratio $(<2.5 \%)$ and SDS-PAGE analysis (Figure 6B). Size-exclusion chromatography elution profile indicated that 100 per cent of the $\mathrm{scFv}_{5} \mathrm{hLi7m}$ was produced as a dimer. The $\mathrm{scFv}_{15} \mathrm{hLi7m}$ was mainly produced as a monomeric molecule but we also observed an additional peak corresponding to misfolded proteins or dimeric structures. The nano-DSF analysis performed with both recombinant proteins in comparison with the first generation molecule did not show any improvement of the thermal stability upon the double mutation and dimerization into a diabody molecule (Figure 6C).

A

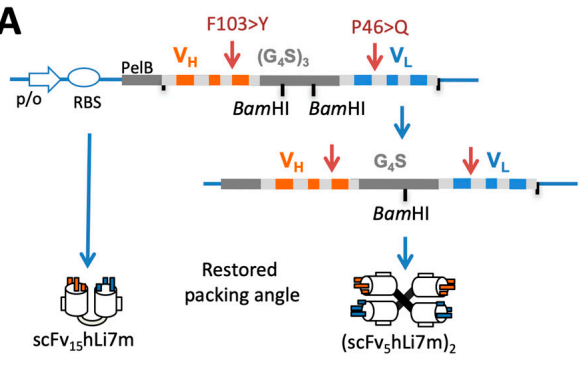

B

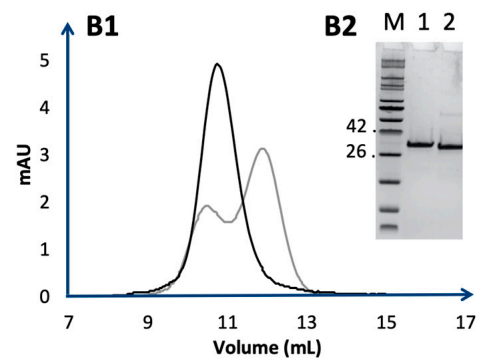

C

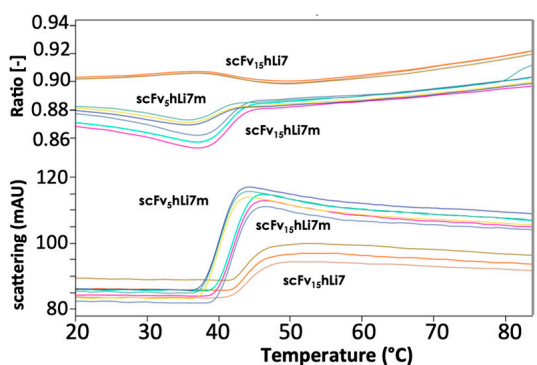

D

\begin{tabular}{|l|l|l|l|}
\hline & $\mathrm{T}_{\text {denaturation }}\left({ }^{\circ} \mathrm{C}\right)$ & $\mathrm{T}_{\mathrm{M}}\left({ }^{\circ} \mathrm{C}\right)$ & $\mathrm{T}_{\text {aggregation }}\left({ }^{\circ} \mathrm{C}\right)$ \\
\hline scFv $_{15} \mathrm{hLi7}$ & $37.00 \pm 0.10$ & $42.23 \pm 0.28$ & $41.79 \pm 0.14$ \\
\hline scFv $_{15} \mathrm{hLi7m}$ & $37.07 \pm 0.06$ & $41.32 \pm 0.04$ & $38.66 \pm 0.17$ \\
\hline scFv $_{5}$ hLi7m & $35.63 \pm 0.06$ & $39.73 \pm 0.07$ & $38.66 \pm 0.15$ \\
\hline
\end{tabular}

Figure 6. Expression, purification and physico-chemical characterization of scFvhLi7m. (A) Schematic representation of the design and expression cassette. The open reading frame contains a PelB signal sequence for periplasmic expression. cDNA encoding humanized VH and VL are fused together via a sequence encoding a $\left(\mathrm{Gly}_{4} \mathrm{Ser}\right)_{3}$ linker and cloned in frame with the PelB sequence. Red arrows indicate back mutations. For expression of $\left(\mathrm{scFv}_{5} \mathrm{hLi} 7 \mathrm{~m}\right)_{2}$, the plasmid was double digested with $B a m \mathrm{HI}$ and then self ligated. (B) Size-exclusion chromatography of the PpL-purified $\mathrm{scFv}_{15} \mathrm{hLi7m}$ (grey) and scFv $_{5}$ hLi7m (black) using a calibrated Superdex 75 10/300GL column (B1). The insert (B2) shows SDS-PAGE analysis of PpL purified $\mathrm{scFv}_{15} \mathrm{hLi7m}(1)$ and $\mathrm{scFv}_{5} \mathrm{hLi7m}$ (2) under reducing conditions. M: Molecular weight marker (kDa). (C) Nano-DSF and thermal stability analysis of PpL purified $\mathrm{scFv}_{15} \mathrm{hLi7m}, \mathrm{scFv}_{5} \mathrm{hLi7m}$ in comparison to the first generation $\mathrm{scFv}_{15} \mathrm{hLi7}$ (each sample was treated in triplicate). (D) On set temperature of denaturation, $\mathrm{T}_{\mathrm{M}}$ and onset temperature of aggregation are indicated in the table.

The preservation of the recognition profile and specificity of the $\mathrm{scFv}_{15} \mathrm{hLi7m}$ and $\mathrm{scFv}_{5} \mathrm{hLi7m}$ fragments against venom components was confirmed after western blotting. When both fragments 
were assessed against the venom of different Loxosceles species, only the L. intermedia venom led to a recognition profile of proteins in the 32-35 kDa molar range, suggesting that the epitope recognized by this fragment is shared by SMaseD isoforms only pertaining to L. intermedia (Figure 7A). The ELISA test was used to compare the affinity of the purified $\mathrm{scFv}_{15} \mathrm{hLi7}, \mathrm{scFv}_{15} \mathrm{hLi7m}$ and $\mathrm{scFv}_{5} \mathrm{hLi7m}$ against a recombinant SMase D and the L. intermedia whole venom. No improvement in affinity was observed for the mutated version when tested against recombinant LiD1, one of the phospholipases present in the Loxtox family (Figure $7 \mathrm{~B}$ ). However, $\mathrm{scF}_{5} \mathrm{hLi7m}$ was able to recognize the L. intermedia whole venom with greater apparent affinity, thus being expected to produce steric hindrance within the different targets present in the venom (Figure 7C).

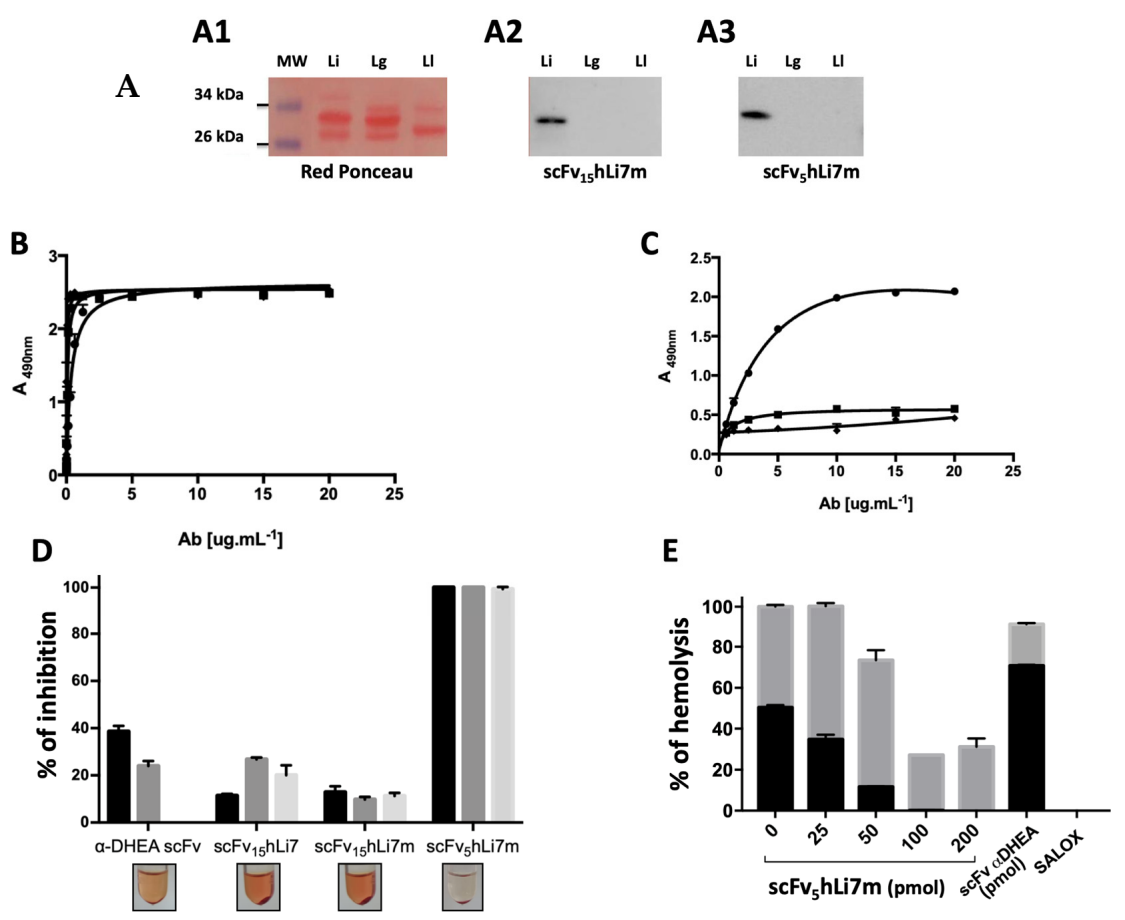

Figure 7. Functional characterization of scFvhLi7m. (A) Western blotting after SDS-PAGE 15\% of $10 \mu \mathrm{g}$ Loxosceles venoms under non-reducing conditions stained with Red Ponceau (A1) or incubated with periplasmic extracts of the $\mathrm{scFv}_{15} \mathrm{hLi7m}$ (A2) and $\mathrm{scFv}_{5} \mathrm{hLi7m}$ (A3), and then developed with peroxidase-conjugated PpL. Li: L. intermedia; Lg: L. gaucho; Ll: L. laeta. (MW) Molecular weight marker (ThermoScientific 26634). (B) Indirect ELISA: immobilized SmaseD LiD1 and added increasing amounts of $\mathrm{scFv}_{15} \mathrm{hLi7}(\boldsymbol{\bullet}), \mathrm{scFv}_{15} \mathrm{hLi7m}(\bullet)$ or $\mathrm{scFv}_{5} \mathrm{hLi7m}(\bullet)$. Immunocomplexes were revealed using peroxidase-conjugated PpL. (C) Indirect ELISA: immobilized L. intermedia venom and added increasing amounts of $\mathrm{scFv}_{15} \mathrm{hLi7}(\boldsymbol{\bullet}), \mathrm{scFv}_{15} \mathrm{hLi7m}(\bullet)$ or $\mathrm{scFv}_{5} \mathrm{hLi7m}(\bullet)$. Immunocomplexes were revealed using peroxidase-conjugated PpL. (D) Inhibition of hemolytic activity. Human erythrocytes were incubated with L. intermedia venom $(0.75 \mu \mathrm{g})$ in the presence of different amounts of antibody: 50 pmol (black), 25 pmol (dark grey) and $12.5 \mathrm{pmol}$ (light grey) for $24 \mathrm{~h}$ under gentle agitation at $37^{\circ} \mathrm{C}$. Ringer buffer was used as a negative control. The results are expressed in percentage of hemolysis inhibition and the venom alone in the absence of antibody was considered as $100 \%$ of hemolysis. Visual inspection of samples is represented in relation to respective antibody fragments. (E) in vitro hemolytic assay. Human erythrocytes were incubated with L. intermedia venom $(10 \mu \mathrm{g})$ in the presence of different concentrations of antibody, with (grey) or without (black) normal human serum. Irrelevant scFv $\alpha$ DHEA (200 pmol) and horse hyperimmune serum (SALOX, 1:500) were used as controls. The results are expressed in percentage of hemolysis and the venom alone, in the absence of antibody, was considered as $100 \%$ of hemolysis. 


\subsection{L. intermedia Venom Neutralization}

In order to assess the humanized antibody fragments capacity to inhibit the hemolytic effects of the L. intermedia venom we performed a hemolysis assay, in presence or absence of the complement system. Different amounts of humanized antibody fragments were incubated with human erythrocytes in the presence of L. intermedia venom $\left(0.75\right.$ and $\left.10 \mu \mathrm{g} \mathrm{mL}^{-1}\right)$. scFv 5 hLi7m (in all molarities) was able to inhibit $100 \%$ of the venom's $\left(0.75 \mu \mathrm{g} \mathrm{mL}^{-1}\right)$ hemolytic activity, when compared to the humanized variants $\mathrm{scFv}_{15} \mathrm{hLi7}$, the $\mathrm{scFv}_{15} \mathrm{hLi7m}$ or the irrelevant $\mathrm{scFv}$ (Figure 7D).

The hemolysis of red blood cells challenged with the venom $(10 \mu \mathrm{g})$ was strongly inhibited $(>90 \%)$ in the presence of 50-200 pmol scFv ${ }_{5} \mathrm{hLi7m}$, when the complement system was absent (Figure 7E). When normal human serum was added to erythrocytes previously incubated with venom and $\mathrm{scFv}_{5} \mathrm{hLi7m}$, an inhibition of up to $68 \%$ of complement-dependent hemolysis was observed (Figure 7E). Horse polyclonal sera anti-L. intermedia venom (SALOX, 1:500) was used as a positive control for hemolysis inhibition under these assay conditions. Additionally, when tested in the presence of $0.75 \mu \mathrm{g} \cdot \mathrm{mL}^{-1}$ and $10 \mu \mathrm{g} \cdot \mathrm{mL}^{-1}$ of L. intermedia venom, Limab7 (50 pmol) was able to neutralize 100 and $80 \%$ of the hemolysis, respectively (data not shown). An irrelevant scFv anti-DHEA was also employed as a negative control [30].

\section{Discussion}

Today, there is no consensus concerning the efficacy of any reported therapy for the treatment of loxoscelism. It is well-established that SMases D play a key role in dermonecrosis and hemolysis, and a number of studies are focusing on the selection of chemical compounds capable of interfering with SMases activity [31]. In this context, the development of neutralizing therapeutic antibodies directed against SMases may also provide an efficient alternative to conventional serum therapy as currently implemented in Brazil. It has been widely reported that many Loxosceles spp. venom proteins induce the production of non-neutralizing antibodies, later present in the total IgG pool of anti-venoms [32,33]. This brings upon the need for the employment of SMases D or their immunorelevant domains as major immunogens in the immunization process, given the significance of these toxins in the course of envenomation [32,34-37]. In addition to this, over the last years, there has been a rising demand for advancements in the conception of anti-venom production. Despite intensive research to develop alternatives for conventional anti-loxoscelism serum therapy, to date, the LimAb7 still remains the only monoclonal antibody able to neutralize the dermonecrotic activity of the L. intermedia venom, as reported by studies in animal models [20]. Recently, we have shown that recombinant LimAb7 antibody fragments (diabodies) preserved in vitro neutralizing capacity of inhibiting SMase D activity, as well as hemolysis induced by L. intermedia venom [22]. However, clinical trials of these molecules in humans is not feasible for safety reasons, unless the antibody's V-domains are humanized. Hence, we designed humanized V-domains and produced them in the scFv format, which is the minimal antibody building block that preserves antigen-binding activity while being well tolerated when administered to humans. We also successfully engineered a PpL binding motif in order to make the purification of antibody fragments using affinity chromatography possible, without requiring the insertion of an epitope tag. This strategy is essential considering future pharmaceutical developments [38-40]. The monomeric $\mathrm{scFv}$ was produced in bacteria and characterized from a physico-chemical point of view. Our functional studies indicated that the humanized scFv preserved its specificity and antigen-binding activity but did not conserve its capacity of neutralizing SMase D activity in vitro. A slight shift in the interaction surface between the targeted toxin and the antibody upon humanization was suspected by antigen/antibody docking analysis. Overall, these apparently disappointing observations underlined the need to fully understand the mechanism of toxin neutralization prior to the design of an antibody fragment with appropriate format for neutralization.

Antibody humanization demands careful study of a molecule's structural and conformational features. The most commonly employed method for humanization consists in grafting murine CDRs into whole human framework regions. Still, it has been demonstrated that some murine framework 
residues, denoted as vernier zone residues, are able to interfere in the CDR loops conformation thus affecting antibody binding affinity [38,41]. Although many methods have been reported for humanization, the immunogenicity of therapeutic antibodies is still a discussed matter [42,43]. The generated antibody fragment must maintain, not only target specificity and high affinity, but also structural and thermal stability as well as preserving or acquiring the capacity to bind to PpL. Considering this, we have produced a minimal size antigen-binding molecule $\left(\mathrm{scFv}_{15} \mathrm{hLi7}\right)$ in order to test the intrinsic properties of its humanized V-domains without the influence of additional constant domains. The humanization process did not lead to molecules producing aggregates and no precipitation or degradation phenomena were detected after SEC-HPLC. This is a positive point, taken that the presence of aggregates in drugs of protein nature can cause adverse effects such as reduced drug efficacy, infusion reactions and potentially hypersensitivity reactions [44-46].

The $\mathrm{scFv}_{15} \mathrm{hLi7}$ exhibited a significantly improved humanness with a Z-score in the range of 0 . It preserved the recognition specificity of the parental antibody LimAb7, even though its affinity significantly decreased when compared to its murine counterpart according to SPR analysis which were carried out under non-optimal conditions. Indeed, the density of LiD1 protein immobilized on the sensorchip was higher than the optimal value for affinity assessment either because of partial misfolding of LiD1 or random covalent immobilization hiding the epitope surface. We anticipate to better evaluate these parameters as additional data is generated using alternative methods which allow the determination of affinity in free solution [47]. Finally, the recombinant antibody showed a limit of detection of $78 \mu \mathrm{g} \cdot \mathrm{mL}^{-1}$ in ELISA and was able to compete with the parental mouse IgG. Still, the humanized LimAb7 V-domains were not able to neutralize the biological activity of the venom or the recombinant sphingomyelinase when expressed in the $\mathrm{scFv}$ format. Aiming to better understand this, we have focused on the SMaseD toxins, which play a key role in loxoscelism. These enzymes have been widely studied and characterized regarding their preferential substrates [48,49], structural basis $[1,2,50,51]$, toxicity $[5,52]$, immunogenicity $[53,54]$ and representativeness in the whole venom [55]. SMases D are also designated dermonecrotic toxins as their recombinant forms have shown to reproduce most of the toxic effects observed in loxoscelism, including dermonecrotic lesions and antigenic properties of the venom [5]. Our SmaseD/LimAb7 and SmaseD/scFv 15 hLi7 docking data clearly support the hypothesis that the interaction between the toxin and the antibody fragments does not occur at the catalytic site of the enzyme. This observation is in agreement with previous overlapping peptide scanning analysis, and also screening of peptide phage-display libraries which identified a putative epitope region located far from the catalytic and $\mathrm{Mg}^{2+}$-binding sites of the enzyme $[28,29,56]$. This is not entirely surprising given that, unlike small neurotoxins which are usually recognized by antibodies at their pharmacological site, larger enzymatic toxins such as PLD are neutralized via other effects such as steric hindrance, making this the first ever reported antibody to neutralize animal toxins via this mechanism [57-59]. With its typical minimal size, the monovalent $\mathrm{scFv}_{15} \mathrm{hLi7}$ could not meet this requirement. The lack of neutralizing ability observed with the $\mathrm{scFv}$ fragments (first $\mathrm{scFv}_{15} \mathrm{hLi} 7$ and later with $\mathrm{scFv}_{15} \mathrm{hLi}$ (m) supports the hypothesis of a steric hindrance mechanism for neutralization. Even more important, the results obtained with the murine IgG or its diabody fragment illustrate the difficulty of choosing the most suitable format in terms of size and valence.

The slight shift in the interaction region with the Smase D observed upon the humanization of LimAb7 V-domains may also have significant consequences regarding the affinity of the antibody fragment for the targeted toxin and also its stability. The decrease in the affinity for the toxin and potentially the non-optimal thermal stability we observed for $\mathrm{scFv}_{15} \mathrm{hLi7}$ could be related to some of the mutations that also altered the $\mathrm{VH} / \mathrm{VL}$ packing angle. Recent studies have shown that a high degree of cooperation between the VH/VL is required for mutual stabilization and also that a limited number of residues buried inside the antibody domain are critical to maintain the topography of the antigen-binding site $[25,39,60]$. The mutation H80 A $>$ R slightly impacts the canonical H2 conformation. A charged residue at this position, close to H58 P (CDR H2) and H30 F (CDR H1), could have led to the disruption of an optimal packing of the CDRs and alter the interaction with 
the target. Hence, residues H103 F > Y; L46 Q > P were back mutated in the revised sequences $\mathrm{scFv}_{15} \mathrm{hLi7m}$ and $\mathrm{scFv}_{5} \mathrm{hLi7m}$, in an attempt to restore some of the parental antibody's binding features. As expected, we observed an increased apparent affinity of the second generation $\mathrm{scFv}_{5} \mathrm{hLi} / \mathrm{m}$ for the immobilized whole venom (ELISA) as compared with $\mathrm{scFv}_{15} \mathrm{hLi7}$. However, this was not the case for the recombinant Smase D LiD1 given that this specific toxin may not be the best representative of the Loxosceles (Loxtox) phospholipase D family targeted by LimAb7. Indeed, the Loxtox family has been extensively characterized and is comprised of a great amount of Smase D isoforms [6], with distinct biological activities (e.g., hemolytic and sphingomyelinase activities were not significant for LiD1, despite producing dermonecrosis in vivo) [53]. We also observed that the thermal stability of the molecule was not optimal and this may be a consequence of some of the mutations introduced. However, the back mutation of residues $\mathrm{H} 103$ and L46, expected to restore the packing angle, did not have any positive impact on the thermal stability. This makes unclear how important it is to preserve the packing angle at least in this particular case study.

The experimental validation of our in-silico docking analysis and humanized fragment re-design was carried out through in vitro hemolysis assays in the presence of the venom and the humanized variants. This approach was selected as a primary screening because it is elucidative and also easier to implement rather than measuring the inhibition of SMase activity in vitro which requires indirect methods with several enzymatic steps sensitive to $\mathrm{pH}$ and other potential irrelevant enzyme inhibitors. The crucial role of hemolysis in the context of Loxosceles spp. envenoming has been thoroughly described, both via direct and complement dependent activation [52,61-63]. The fact that only the diabody neutralizes the hemolysis validates the docking predictions and confirms that neutralization occurs via a steric hindrance mechanism, and corroborates well with previous experiments carried out independently using other experimental strategies [56].

Our findings report for the first time the successful production of a humanized antibody fragment able to neutralize L. intermedia venom hemolytic activity in vitro, in a complement dependent $(68 \%$ of neutralization) and independent manner (100\% of neutralization). Therefore, the humanized diabody $\left(\mathrm{scFv}_{5} \mathrm{Li} 7 \mathrm{~m}\right)$ paves the way for the development of therapeutic recombinant antibodies in loxoscelism. Major advantages of this approach can be foreseen. Immunization of big warm blood animals would no longer be required for production of antivenoms. Additionally, antibody fragments would be prepared without requiring any enzymatic fragmentation that is often deleterious in terms of antigen-binding activity. The specific activity would be higher than the one of polyclonal antivenoms that contain many irrelevant antibodies. Finally, the cDNA encoding the recombinant antibody fragment would be available indefinitely while polyclonal antibodies are never rigorously defined and vary from batch to batch. Of course, diabodies may not be appropriate for human injection due to short half-life and potentially low thermal stability [64]. However, these molecules can be re-designed into Fab fragments which format has yet been proven to be more stable, suitable for human infusion and efficient for the treatment of several diseases [65]. In a Fab, both VH/VL and CH/CL interactions contribute to the functional stability of the antibody fragment and potentially to the in vivo toxin neutralization capacity as suggested previously [66]. In addition, one can consider site-specific PEGylation of scFvs for enhancing the pharmacokinetic properties, the conformational stability, protection from proteolysis and immunogenicity [67]. Altogether, these findings represent a proof of concept on humanized mouse antibodies specific to animal toxins, encouraging the optimized production of molecules for in vivo assessment.

\section{Materials and Methods}

\subsection{Venoms and Toxins}

Vacuum dried venoms from L. laeta, L. gaucho, and L. intermedia spiders were provided by Centro de Produção e Pesquisa de Imunobiológicos (CPPI, Piraquara, Brazil) and resuspended in a $10 \mathrm{mM}$ $\mathrm{Na}_{2} \mathrm{HPO}_{4}$ buffer containing $137 \mathrm{mM} \mathrm{NaCl}$ and $2.7 \mathrm{mM} \mathrm{KCl}$ (PBS), pH 7.4 at a concentration of 
0.8-1 mg.mL ${ }^{-1}$. The recombinant SMase D LiD1 from L. intermedia (Uniprot: P0CE81), presenting 99.67\% of identity with LiRecDT1 (PDB: 3RLH) was a gift from Dr. Felicori Figueredo (UFMG, Belo Horizonte, Brazil) (Genbank accession number: AY340702).

\subsection{Monoclonal and Polyclonal Antibodies}

The LimAb7 hybridoma was produced after the immunization of adult female BALB/c mice with $L$. intermedia venom. It has been previously shown to secrete a well-characterized monoclonal $\mathrm{IgG}_{1 \mathrm{k}}$ that neutralizes the democratic activity of L. intermedia spider venom, and binds to the SMase D LiD1 as well as several other $32-35 \mathrm{kD}$ related proteins of the L. intermedia venom, interestingly, not cross-reacting with any components of L. laeta and L. gaucho venoms, given their considerable interspecies homology $[20,56]$. Horse hyperimune sera (SALOX) reactive to L. intermedia, L. laeta, and L. gaucho venoms was produced by CPPI. Horse $\operatorname{IgG~F(ab){}_{2}}$ anti-L. intermedia venom was prepared as previously reported [20].

\subsection{Bacteria}

The Escherichia coli AD494 (DE3) pLysS strain (Novae, Nottingham, UK) and HB2151 (Stratagene, La Jolla, CA, USA) were selected for protein expression. Bacteria culture media was purchased from AthenaES (Baltimore, MD, USA) and all chemicals were of standard grade and acquired from Sigma Aldrich (St. Louis, MO, USA) or equivalent.

\subsection{Protein Quantification}

Protein concentration was determined by the Bradford reagent (Bio-Rad Laboratories, Hercules, CA, USA). Alternatively, purified protein concentration was measured by the absorbance at $280 \mathrm{~nm}$ using, for each purified protein, the molar extinction coefficients $(\varepsilon)$ determined as previously reported [68].

\subsection{Humanization of Antibody V-Domains}

The structure of mouse LimAb7 Fv (Genbank accession number KT381972) was previously modeled [69]. Amino acid numbering and sequence analysis were carried out using the Web interface IMGT tools and database (IMGT/DomainGapAlign). Humanized versions of LimAb7 V-domains were generated by grafting all six CDRs onto human IGKV and IGHV domains having high sequence identity and closely related canonical classes with LimAb7 V-domains. The protocol was adapted from a previous one [24]. After grafting the CDRs to human FR regions, each amino acid (AA) substitution was inspected individually, based on the physico-chemical classes of the AA differences [70]. We considered the humanness score (Z-score), which compares the sequences with a set of known human sequences assigned to germline derived families, aiming to achieve a score close or above 0 [71]. VH/VL packing angle and residues that might play an important role in maintaining the correct binding-site topography were identified [25]. Additional refinements were carried out in IGKV-FR1 in order to generate a PpL-binding site without altering predicted humanization and residual immunogenicity as previously suggested $[27,72]$. Finally, the designed sequences were compared with human germline genes in order to calculate a human germinality [73].

\subsection{Generation and Purification of Humanized $s c F v_{15} h L i 7$ and $s c F v_{5} h L i 7 m$}

Codon optimized DNA encoding humanized V-domains fused together in the VH-VL orientation via a sequence encoding the $\left(\mathrm{G}_{4} \mathrm{~S}\right)_{3}$ linker were synthesized at Genscript (Piscataway, NJ, USA) and cloned into the prokaryotic expression vectors pET-22b (+) or pSW1, in frame with the PelB signal sequence [74]. 
Production and PpL-purification of $\mathrm{scFv}_{15} \mathrm{hLi7}$ (first generation of the humanized scFv) were carried out under generic conditions at Genscript. Purified $\mathrm{scFv}_{15} \mathrm{hLi}$ concentration was adjusted to $0.57 \mathrm{mg} \cdot \mathrm{mL}^{-1}$ in PBS $\mathrm{pH}$ 7.2. Aliquoted samples were stored at $-80^{\circ} \mathrm{C}$.

For the $\mathrm{scFv}_{15} \mathrm{hLi7m}$ 's (second generation of the humanized scFv) construction, two BamHI restriction sites were introduced in the nucleotide sequence encoding the $\left(\mathrm{G}_{4} \mathrm{~S}\right)_{3}$ linker. Therefore, double digestion with Bam $\mathrm{HI}$ followed by self-ligation of the plasmid allowed the generation of a vector encoding diabody $\mathrm{scFv}_{5} \mathrm{hLi7m}$ which differs from $\mathrm{scFv}_{15} \mathrm{hLi} 7 \mathrm{~m}$ by the size of its linker peptide $\left(\mathrm{G}_{4} \mathrm{~S}\right)$. Both scFvs were produced by E. coli AD494 (DE3) pLysS bacteria transformed with vector pET-22b (+) containing the insert of interest as previously described [22]. Alternatively, we used HB2151 strains transformed with $\mathrm{pSW} 1$ vector for $\mathrm{scFv}$ production under generic conditions and PpL capture [75]. The scFv-containing fractions were pooled and subjected to dialysis in PBS, pH 7.4 overnight at $4{ }^{\circ} \mathrm{C}$.

\subsection{SDS-PAGE, Western Blot and Dot Blot}

To assess bacterial periplasmic extracts for scFv expression, samples were resolved by SDS-PAGE under non-reducing conditions on $12.5 \%$ polyacrylamide gel. Proteins migrated at $150 \mathrm{~V}$ for $2 \mathrm{~h}$ at room temperature. Subsequently, gels were either stained with Coomassie Brilliant Blue for protein identification or transferred onto a $0.45 \mathrm{~mm}$ nitrocellulose membrane, for $2 \mathrm{~h}, 100 \mathrm{~V}$ at $4{ }^{\circ} \mathrm{C}$. The quality of the transfer was checked by transitional staining with Red Ponceau. In order to verify the expression of the scFvs, the membrane's non-specific binding sites were first blocked for $1 \mathrm{~h}$ in PBS containing $5 \%(\mathrm{w} / \mathrm{v})$ non-fat dry milk and $0.3 \%(\mathrm{v} / \mathrm{v})$ Tween 20 . Next, membranes were incubated with peroxidase-conjugated PpL (ThermoFisher, Waltham, MA, USA) in PBS, pH 7.4, containing $0.05 \%$ Tween 20, for $1 \mathrm{~h}$ at $37^{\circ} \mathrm{C}$ and stained with DAB/chloronaphtol.

Aiming to confirm the fragments specificity against the L. intermedia venom, the periplasmic extracts were analysed by dot blot. Firstly, L. laeta, L. gaucho, and L. intermedia venom (2.5 $\mu \mathrm{g}$ each) were immobilized on to nitrocellulose membrane, then the non-specific binding sites were blocked with non-fat milk as described above. Next, membranes were incubated with the scFv periplasmic extracts (for $1 \mathrm{~h}$ at $37^{\circ} \mathrm{C}$ ) and after with peroxidase-conjugated PpL (ThermoFisher) for scFv detection. Lastly, membranes were stained with DAB/chloronaphtol.

Additionally, L. laeta, L. gaucho, L. intermedia venoms, and recombinant Smase D LiD1 were subjected to an SDS-PAGE on a $15 \%$ acrylamide gel and transferred onto a $0.45 \mathrm{~mm}$ nitrocellulose membrane in order to verify the scFv's binding to the dermonecrotic toxins. The immunocomplexes were detected with peroxidase-conjugated PpL (ThermoFisher) or peroxidase-conjugated rabbit anti-mouse IgG (Sigma Aldrich, 1:4000). Between all intermediate steps, three washings with PBS ( $\mathrm{pH}$ 7.4) containing $0.05 \%$ Tween 20 were performed.

\subsection{UV-Vis Analysis}

UV-Vis spectra (from 220 to $350 \mathrm{~nm}$ ) were carried out in triplicate after dilution of samples at the $0.5 \mathrm{AU}_{280 \mathrm{~nm}}$ in PBS pH 7.2.

\subsection{Size-Exclusion Chromatography}

$100 \mu \mathrm{L}$ of PpL-purified scFv (2 or $10 \mu \mathrm{M})$ were analysed by size-exclusion high pressure liquid chromatography (SEC-HPLC) using a prepacked Superdex 75 10/300 GL column calibrated with standards from GE Healthcare (Buc, France). Proteins were eluted with PBS pH 7.2 at a rate of $0.5 \mathrm{~mL} \cdot \mathrm{min}^{-1}$ and detected with a UV recorder at $280 \mathrm{~nm}$.

\subsection{Circular Dichroism}

CD spectra were obtained on a Model CD6 spectrometer (Jobin-Yvon-Spex, Longjumeau, France) at different temperatures from 15 to $60^{\circ} \mathrm{C}$ using a thermoregulated bath using a quartz sample cell with a $1 \mathrm{~mm}$ path length. The ellipticity was scanned from 200 to $250 \mathrm{~nm}$ with an increment of $1 \mathrm{~nm}$, an 
integration time of $2 \mathrm{~s}$, and a constant band-pass of $2 \mathrm{~nm}$. The concentration of the $\mathrm{scFv}_{15} \mathrm{hLi7}$ protein was adjusted to $0.114 \mathrm{mg} \cdot \mathrm{mL}^{-1}$ in PBS, $\mathrm{pH} 7.4$.

\subsection{Nano-DSF}

The samples $(10 \mu \mathrm{M})$ were loaded in standard nano-DSF capillaries and measured using the Prometheus NT.48 instrument (NanoTemper, Munich, Germany) containing aggregation optics. The LED intensity was set to $10 \%$, whereas the temperature ramp was set from 20 to $95^{\circ} \mathrm{C}$ with $1{ }^{\circ} \mathrm{C}$ per $\mathrm{min}$. As negative control one duplicate was integrated containing heat denatured protein.

\subsection{Enzyme-Linked Immunosorbent Assay}

Sandwich ELISA: Plates (Nunc MaxiSorp ${ }^{\mathrm{TM}}$, ThermoFisher) were coated with $100 \mu \mathrm{L}$ of a $10 \mu \mathrm{g} \cdot \mathrm{mL}^{-1}$ solution of IgG $\mathrm{F}(\mathrm{ab})^{\prime}{ }_{2}$ horse anti- L. intermedia venom in carbonate buffer $\mathrm{pH} 9.6$ at $4{ }^{\circ} \mathrm{C}$ overnight. After blocking ( $2 \%$ casein in PBS), $100 \mu \mathrm{L}$ of L. intermedia venom $\left(0.039-10 \mu \mathrm{g} \cdot \mathrm{mL}^{-1}\right)$ were added and incubated for $1 \mathrm{~h}$ at $37^{\circ} \mathrm{C}$. The plates were washed and incubated with solution of $\mathrm{scFv}_{15} \mathrm{hLi7}\left(20 \mu \mathrm{g} \cdot \mathrm{mL}^{-1}\right)$. Lastly, $100 \mu \mathrm{L}$ of peroxidase-conjugated PpL (ThermoFisher) were added for $1 \mathrm{~h}$ at room temperature.

Competitive ELISA: Plates were coated with L. intermedia venom $\left(100 \mu \mathrm{L}, 10 \mu \mathrm{g} \mathrm{mL}^{-1}\right)$ for $16 \mathrm{~h}$ at $4{ }^{\circ} \mathrm{C}$ and then saturated with $2 \%$ casein diluted in PBS for $60 \mathrm{~min}$, at $37^{\circ} \mathrm{C}$. Next, solutions containing LimAb7 $\left(1 \mu \mathrm{g} \cdot \mathrm{mL}^{-1}\right)$ and scFv $15 \mathrm{hLi7}\left(6.25-100 \mu \mathrm{g} \cdot \mathrm{mL}^{-1}\right)$ were incubated for $1 \mathrm{~h}$, at $37^{\circ} \mathrm{C}$. Immunocomplexes formed with the IgG were detected by adding peroxidase-conjugated anti-mouse IgG (1:4.000, Sigma, St. Louis, MO, USA).

Indirect ELISA: Plates were coated with L. intermedia venom or SMase D Lid1 $\left(100 \mu \mathrm{L}, 2.5 \mu \mathrm{g} \cdot \mathrm{mL}^{-1}\right)$ for $16 \mathrm{~h}$ at $4{ }^{\circ} \mathrm{C}$, and then saturated with $2 \%$ casein diluted in PBS for $60 \mathrm{~min}$. Further, different concentrations of scFv $\left(0.156-20 \mu \mathrm{g} \cdot \mathrm{mL}^{-1}\right)$ were added at $37^{\circ} \mathrm{C}$ for $1 \mathrm{~h}$. Immunocomplexes were detected by adding peroxidase-conjugated PpL (ThermoFisher).

In both ELISA formats, immunocomplexes were revealed by the addition of substrate (0.2\% 2,2/-6azino-bis (2-ethylbenzthiazoline-6-sulphonic acid) to a $0.05 \mathrm{M}$ citric acid buffer, $\mathrm{pH} 4.0$ containing $0.015 \%$ hydrogen peroxide (Sigma, St. Louis, MO, USA), for $15 \mathrm{~min}$. Absorbance at 405 $\mathrm{nm}$ was measured using an ELISA plate reader. All incubation steps were carried out at $37^{\circ} \mathrm{C}$. All assays were conducted in triplicates. ELISA standard curves were fitted by non-linear regression, using the Saturation Binding - One site -Specific binding function. Statistical analyses and graphics were performed in GraphPad Prism v7.0 for MacOSX (GraphPad Software, San Diego, CA, USA).

\subsection{SPR Analysis}

The BIAcore T100 instrument and all reagents were obtained from GE Healthcare Life Sciences, SMase D LiD1 was covalently attached to a CM5-sensor chip using standard amine coupling through EDC/NHS chemistry (approximately $3500 \mathrm{RU}$ ). The purified IgG and scFv diluted in PBS, pH 7.4, were passed over the immobilized target (LiD1) at a flow rate of $30 \mu \mathrm{L} \cdot \mathrm{min}^{-1}$ for $1 \mathrm{~min}$ at $25^{\circ} \mathrm{C}$. The binding kinetics were analyzed using the single-cycle kinetic method with no regeneration between sample injections. Experimental Rmax were $8750 \mathrm{RU}$ and $2900 \mathrm{RU}$ for the IgG and the scFv, respectively. Kinetic constants $\left(\mathrm{k}_{\mathrm{a}}, \mathrm{k}_{\mathrm{d}}\right)$ were deduced from the analysis of association and dissociation rates of at least four different antibody concentrations $(0.125 \mu \mathrm{M}-2.0 \mu \mathrm{M})$. The dissociation constant $\mathrm{K}_{\mathrm{D}}$ was calculated as $\mathrm{K}_{\mathrm{D}}=\mathrm{k}_{\mathrm{a}} / \mathrm{k}_{\mathrm{d}}$. Sensorgrams were analysed using the BIA evaluation version 2.0.2 software (GE Healthcare, Vélizy-Villacoublay, France). All experiments were carried out in duplicate.

\subsection{Modelling and Molecular Docking}

In order to investigate which amino acid residues might participate in the antigen-antibody interaction, we performed homology modelling of murine monoclonal antibody $\mathrm{LimAb7}$ and $\mathrm{scFv}_{15} \mathrm{hLi} 7$ using the MODELLER tool (version 9.19, UCSF-University of California, San Francisco (UCSF), San Francisco, CA, USA) [76]. In this step, antibody sequences were aligned through a BLAST [77] 
search and their templates were identified based on sequence identity, query coverage and E-value criteria (Table S2). Utilizing the template choices for each antibody, 1000 models were generated with the MODELLER tool (9.2v) and then selected according to their ZDOPE score values [78]. Subsequently, model quality was evaluated by comparing the predicted structures with their respective templates via superimposition and atomic RMSD (root mean square deviation) assessment. The chosen cu-off RMSD values of C $\alpha$ trace between all homology structures and templates was $<2.00 \AA$. Moreover, model energy minimization and loop refinement were carried out in attempt to increase the model's quality (Ramachandran plot) using the Chimera software [79] and MODELLER tool, ensuring more than $90 \%$ of models' AA residues were in favored Ramachandran Plot regions. After modelling the three structures, the ClusPro2.0 server (Boston University (BU), Boston, MA, USA) [80] was used to predict the interactions between the modelled antibodies and the Smase D LiRecDT1 (PDB: 3RLH). The LiRecDT1 SMase was selected instead of SMase LiD1 given its X-ray data is available and it only differs from LiD1 by two AA residues. The antibody mode was selected with the non-CDR regions masked automatically [81]. The antibody structures were submitted as the receptor and SMase D LiRecDT1 as the ligand. ClusPro selected the 1000 best scoring solutions, clustered them according to RMSD criteria, and the lowest ClusPro energy score, representing the greatest probability of antigen-antibody interaction, was selected [80]. Amino acid contacts and interaction parameters between the antibodies and their targets were assessed through the PDBSum online platform [82].

\subsection{Neutralization of the Hemolytic Activity}

Blood from human healthy donors was collected in tubes containing sodium citrate buffer (BD Plastipak, Franklin Lakes, NJ USA). The platelet-rich plasma and buffy coat were removed by aspiration after centrifugation at 200× $g$ for $15 \mathrm{~min}$. Packed erythrocytes were washed three times with Ringer Solution (125 mM NaCl, 5 mM KCl, 1 mM MgSO 4 , 32 mM HEPES, 5 mM glucose, $1 \mathrm{mM}$ $\mathrm{CaCl}_{2}, \mathrm{pH} 7.4,300 \mathrm{mOsm} / \mathrm{kg} \mathrm{H}_{2} \mathrm{O}$ ) and redissolved at a final concentration of $10^{8}$ cells $\cdot \mathrm{mL}^{-1}$. In order to evaluate the neutralization potential of the antibodies, $0.75 \mu \mathrm{g}$ of venom were incubated with the following antibody molarities (12.5-50 pmol). After $24 \mathrm{~h}$ of gentle agitation and incubation at $37^{\circ} \mathrm{C}$, samples were centrifuged $(5 \mathrm{~min}, 200 \times \mathrm{g}$ ) and the absorbance at $570 \mathrm{~nm}$ of the supernatants was read. Samples were analyzed in triplicates along with negative (Ringer solution) and positive (distilled water containing $0.1 \%(\mathrm{v} / \mathrm{v})$ Triton X-100) controls. Absorbance values were converted to percentage of hemolysis considering the absorbance at $570 \mathrm{~nm}$ of $0.75 \mu \mathrm{g}$ of venom as $100 \%$ lysis.

Subsequently, the inhibition of hemolysis was evaluated in the presence of the components of the complement system. In order to do this, a $1 \mathrm{~mL}$ solution containing $10^{8}$ erythrocytes was treated with $L$. intermedia venom $(10 \mu \mathrm{g})$ in the presence of different antibody quantities (25-200 pmol) for $24 \mathrm{~h}$ under gentle agitation and incubation at $37^{\circ} \mathrm{C}$. Samples were centrifuged $(5 \mathrm{~min}, 200 \times g)$ and the absorbance at $570 \mathrm{~nm}$ of the supernatants was read. Next, erythrocytes were washed three times with Ringer solution and incubated with $500 \mu \mathrm{L}$ of a solution of normal human serum, diluted 1:2, for one hour at $37^{\circ} \mathrm{C}$. Unlysed cells were centrifuged and the absorbance of the supernatant was measured at $570 \mathrm{~nm}$ and expressed as percentage of hemolysis. After subtracting all samples absorbance from the absorbance at $570 \mathrm{~nm}$ obtained from Ringer treated erytrocytes, before and after complement incubation, the lysis percentage (absorbance sample / (absorbance venom without/ complement + absorbance venom with / complement) $) \times 100$ was calculated considering the sum of the absorbance at $570 \mathrm{~nm}$ of the venom before complement incubation and absorbance at $570 \mathrm{~nm}$ of venom after complement incubation as $100 \%$ of hemolysis. Mean and standard deviation were determined from duplicate samples.

This study has been approved by the human research ethics committee from Setor de Ciências da Saúde do Universidade Federal do Paraná (Curitiba, Brazil) under the certificate number CEP/SD2911004, CAAE:93959218.7.0000.0102 on 24 September 2018.

Supplementary Materials: The following are available online at http://www.mdpi.com/2072-6651/12/4/256/s1, Table S1: Hydrogen Bonds between the amino acid residues of the antibodies and Lid1, Table S2: In silico modeling data. 
Author Contributions: Contributed to the conception, and the design of the study, L.M.A., P.B., N.A. and J.d.M.; performed the functional analysis, S.K.-S., A.B.-F., I.G.J. and F.B.; performed modelling and docking experiments, I.G.J.; in charge of Far-UV CD analysis and interpretation, A.L.; performed SPR analysis, M.N.; wrote the manuscript, L.M.A., I.G.J. and P.B. All authors have read and agreed to the published version of the manuscript.

Funding: This study was supported by conselho nacional de desenvolvimento científico e tecnológico, CNPq, Brazil (No.401355/2014-4, No. 472460/2013-7), Fundação Araucária No. 04/2013, Coordenação de Aperfeiçoamento de Pessoal de Nível Superior-Brasil (CAPES)-Finance Code 001, and the french higher education and research ministry under the program "Investissements d'avenir" (LabEx MAbImprove ANR-10-LABX-53-01). CNPq also granted $\mathrm{PB}$ with a special visiting researcher fellowship under the brazilian scientific mobility program "Ciências sem Fronteiras".

Conflicts of Interest: The authors declare that the research was conducted in the absence of any commercial or financial relationships that could be considered as a potential conflict of interest.

\section{References}

1. Chaves-Moreira, D.; Senff-Ribeiro, A.; Wille, A.C.M.; Gremski, L.H.; Chaim, O.M.; Veiga, S.S. Highlights in the knowledge of brown spider toxins. J. Venom. Anim. Toxins Incl. Trop. Dis. 2017, 23, 6. [CrossRef] [PubMed]

2. Cordeiro, F.A.; Amorim, F.G.; Anjolette, F.A.P.; Arantes, E.C. Arachnids of medical importance in Brazil: Main active compounds present in scorpion and spider venoms and tick saliva. J. Venom. Anim. Toxins Incl. Trop. Dis. 2015, 21, 24. [CrossRef] [PubMed]

3. Ministério da Saúde. Brasília: Brasil. Sistema de Informação de Agravos de Notificação SINAN. Available online: http://tabnet.datasus.gov.br/cgi/deftohtm.exe?sinannet/cnv/animaisbr.def (accessed on 1 February 2020).

4. Swanson, D.L.; Vetter, R.S. Loxoscelism. Clin. Dermatol. 2006, 24, 213-221. [CrossRef] [PubMed]

5. Gremski, L.H.; Trevisan-Silva, D.; Ferrer, V.P.; Matsubara, F.H.; Meissner, G.O.; Wille, A.C.M.; Vuitika, L.; Dias-Lopes, C.; Ullah, A.; de Moraes, F.R.; et al. Recent advances in the understanding of brown spider venoms: From the biology of spiders to the molecular mechanisms of toxins. Toxicon 2014, 83, 91-120. [CrossRef] [PubMed]

6. Gremski, L.H.; da Justa, H.C.; da Silva, T.P.; Polli, N.L.C.; Antunes, B.C.; Minozzo, J.C.; Wille, A.C.M.; Senff-Ribeiro, A.; Arni, R.K.; Veiga, S.S. Forty years of the description of brown spider venom phospholipases-D. Toxins 2020, 12, 164. [CrossRef] [PubMed]

7. Wille, A.C.M.; Chaves-Moreira, D.; Trevisan-Silva, D.; Magnoni, M.G.; Boia-Ferreira, M.; Gremski, L.H.; Gremski, W.; Chaim, O.M.; Senff-Ribeiro, A.; Veiga, S.S. Modulation of membrane phospholipids, the cytosolic calcium influx and cell proliferation following treatment of B16-F10 cells with recombinant phospholipase-D from Loxosceles intermedia (brown spider) venom. Toxicon 2013, 67, 17-30. [CrossRef]

8. Kalapothakis, E.; Araujo, S.C.; de Castro, C.S.; Mendes, T.M.; Gomez, M.V.; Mangili, O.C.; Gubert, I.C.; Chávez-Olórtegui, C. Molecular cloning, expression and immunological properties of LiD1, a protein from the dermonecrotic family of Loxosceles intermedia spider venom. Toxicon 2002, 40, 1691-1699. [CrossRef]

9. Pedrosa, M.d.F.F.; de Azevedo, I.D.L.J.; Gonçalves-de-Andrade, R.M.; van den Berg, C.W.; Ramos, C.R.R.; Ho, P.L.; Tambourgi, D.V. Molecular cloning and expression of a functional dermonecrotic and haemolytic factor from Loxosceles laeta venom. Biochem. Biophys. Res. Commun. 2002, 298, 638-645. [CrossRef]

10. Da Silveira, R.B.; Pigozzo, R.B.; Chaim, O.M.; Appel, M.H.; Dreyfuss, J.L.; Toma, L.; Mangili, O.C.; Gremski, W.; Dietrich, C.P.; Nader, H.B.; et al. Molecular cloning and functional characterization of two isoforms of dermonecrotic toxin from Loxosceles intermedia (brown spider) venom gland. Biochimie 2006, 88, 1241-1253. [CrossRef]

11. Da Silveira, R.B.; Pigozzo, R.B.; Chaim, O.M.; Appel, M.H.; Silva, D.T.; Dreyfuss, J.L.; Toma, L.; Dietrich, C.P.; Nader, H.B.; Veiga, S.S.; et al. Two novel dermonecrotic toxins LiRecDT4 and LiRecDT5 from brown spider (Loxosceles intermedia) venom: From cloning to functional characterization. Biochimie 2007, 89, 289-300. [CrossRef]

12. Appel, M.H.; da Silveira, R.B.; Chaim, O.M.; Paludo, K.S.; Silva, D.T.; Chaves, D.M.; da Silva, P.H.; Mangili, O.C.; Senff-Ribeiro, A.; Gremski, W.; et al. Identification, cloning and functional characterization of a novel dermonecrotic toxin (phospholipase D) from brown spider (Loxosceles intermedia) venom. Biochim. Biophys. Acta 2008, 1780, 167-178. [CrossRef] [PubMed] 
13. Ullah, A.; de Giuseppe, P.O.; Murakami, M.T.; Trevisan-Silva, D.; Wille, A.C.M.; Chaves-Moreira, D.; Gremski, L.H.; da Silveira, R.B.; Sennf-Ribeiro, A.; Chaim, O.M.; et al. Crystallization and preliminary X-ray diffraction analysis of a class II phospholipase D from Loxosceles intermedia venom. Acta Crystalogr. Sect. F Struct. Biol. Cryst. Commun. 2011, 67, 234-236. [CrossRef] [PubMed]

14. Hogan, C.J.; Barbaro, K.C.; Winkel, K. Loxoscelism: Old obstacles, new directions. Ann. Emerg. Med. 2004, 44, 608-624. [CrossRef] [PubMed]

15. Isbister, G.K.; Fan, H.W. Spider bite. Lancet 2011, 378, 2039-2047. [CrossRef]

16. Pauli, I.; Minozzo, J.C.; da Silva, P.H.; Chaim, O.M.; Veiga, S.S. Analysis of therapeutic benefits of antivenin at different time intervals after experimental envenomation in rabbits by venom of the brown spider (Loxosceles intermedia). Toxicon 2009, 53, 660-671. [CrossRef]

17. Guilherme, P.; Fernandes, I.; Barbaro, K.C. Neutralization of dermonecrotic and lethal activities and differences among 32-35 kDa toxins of medically important Loxosceles spider venoms in Brazil revealed by monoclonal antibodies. Toxicon 2001, 39, 1333-1342. [CrossRef]

18. Ramada, J.S.; Becker-Finco, A.; Minozzo, J.C.; Felicori, L.F.; Machado de Avila, R.A.; Molina, F.; Nguyen, C.; de Moura, J.; Chávez-Olórtegui, C.; Alvarenga, L.M. Synthetic peptides for in vitro evaluation of the neutralizing potency of Loxosceles antivenoms. Toxicon 2013, 73, 47-55. [CrossRef]

19. Laustsen, A.H.; Solà, M.; Jappe, E.C.; Oscoz, S.; Lauridsen, L.P.; Engmark, M. Biotechnological trends in spider and scorpion antivenom development. Toxins 2016, 8, 226. [CrossRef]

20. Alvarenga, L.M.; Martins, M.S.; Moura, J.F.; Kalapothakis, E.; Oliveira, J.C.; Mangili, O.C.; Granier, C.; Chávez-Olórtegui, C. Production of monoclonal antibodies capable of neutralizing dermonecrotic activity of Loxosceles intermedia spider venom and their use in a specific immunometric assay. Toxicon 2003, 42, 725-731. [CrossRef]

21. Dias-Lopes, C.; Felicori, L.; Rubrecht, L.; Cobo, S.; Molina, L.; Nguyen, C.; Galéa, P.; Granier, C.; Molina, F.; Chávez-Olortegui, C. Generation and molecular characterization of a monoclonal antibody reactive with conserved epitope in sphingomyelinases D from Loxosceles spider venoms. Vaccine 2014, 32, 2086-2092. [CrossRef]

22. Karim-Silva, S.; de Moura, J.; Noiray, M.; Minozzo, J.C.; Aubrey, N.; Alvarenga, L.M.; Billiald, P. Generation of recombinant antibody fragments with toxin-neutralizing potential in loxoscelism. Immunol. Lett. 2016, 176, 90-96. [CrossRef] [PubMed]

23. Harding, F.A.; Stickler, M.M.; Razo, J.; DuBridge, R.B. The immunogenicity of humanized and fully human antibodies. MAbs 2010, 2, 256-265. [CrossRef] [PubMed]

24. Aubrey, N.; Billiald, P. Antibody fragments humanization: Beginning with the end in mind. Methods Mol. Biol. 2019, 1904, 231-252.

25. Abhinandan, K.R.; Martin, A.C.R. Analysis and prediction of VH/VL packing in antibodies. Protein Eng. Des. Sel. 2010, 23, 689-697. [CrossRef] [PubMed]

26. Gao, S.H.; Huang, K.; Tu, H.; Adler, A.S. Monoclonal antibody humanness score and its applications. Bmc Biotechnol. 2013, 13, 55. [CrossRef]

27. Lakhrif, Z.; Pugnière, M.; Henriquet, C.; di Tommaso, A.; Dimier-Poisson, I.; Billiald, P.; Juste, M.O.; Aubrey, N. A method to confer Protein L binding ability to any antibody fragment. MAbs 2016, 8, 379-388. [CrossRef]

28. Murakami, M.T.; Fernandes-Pedrosa, M.F.; Tambourgi, D.V.; Arni, R.K. Structural basis for metal ion coordination and the catalytic mechanism of sphingomyelinases D. J. Biol. Chem. 2005, 280, 13658-13664. [CrossRef]

29. Vuitika, L.; Chaves-Moreira, D.; Caruso, I.; Lima, M.A.; Matsubara, F.H.; Murakami, M.T.; Takahashi, H.K.; Toledo, M.S.; Coronado, M.A.; Nader, H.B.; et al. Active site mapping of Loxosceles phospholipases D: Biochemical and biological features. Biochim. Biophys. Acta 2016, 1861, 970-979. [CrossRef]

30. Fogaça, R.L.; Alvarenga, L.M.; Woiski, T.D.; Becker-Finco, A.; Teixeira, K.N.; Silva, S.K.; de Moraes, R.N.; de Noronha, L.; Noiray, M.; de Figueiredo, B.C.; et al. Biomolecular engineering of antidehydroepiandrosterone antibodies: A new perspective in cancer diagnosis and treatment using single-chain antibody variable fragment. Nanomedicine 2019, 14, 689-705. [CrossRef]

31. Lopes, P.H.; Murakami, M.T.; Portaro, F.C.V.; Mesquita Pasqualoto, K.F.; van den Berg, C.; Tambourgi, D.V. Targeting Loxosceles spider Sphingomyelinase D with small-molecule inhibitors as a potential therapeutic approach for loxoscelism. J. Enzym. Inhib. Med. Chem. 2019, 34, 310-321. [CrossRef] 
32. de Almeida, D.M.; de Fernandes-Pedrosa, M.F.; de Andrade, R.M.G.; Marcelino, J.R.; Gondo-Higashi, H.; de Azevedo, I.L.M.J.; Ho, P.L.; van den Berg, C.; Tambourgi, D.V. A new anti-loxoscelic serum produced against recombinant sphingomyelinase D: Results of preclinical trials. Am. J. Trop. Med. Hyg. 2008, 79, 463-470. [CrossRef] [PubMed]

33. Duarte, C.G.; Bonilla, C.; Guimarães, G.; Machado de Avila, R.A.; Mendes, T.M.; Silva, W.; Tintaya, B.; Yarleque, A.; Chávez-Olórtegui, C. Anti-loxoscelic horse serum produced against a recombinant dermonecrotic protein of Brazilian Loxosceles intermedia spider neutralize lethal effects of Loxosceles laeta venom from Peru. Toxicon 2015, 93, 37-40. [CrossRef] [PubMed]

34. Felicori, L.; Fernandes, P.B.; Giusta, M.S.; Duarte, C.G.; Kalapothakis, E.; Nguyen, C.; Molina, F.; Granier, C.; Chávez-Olórtegui, $\mathrm{C}$. An in vivo protective response against toxic effects of the dermonecrotic protein from Loxosceles intermedia spider venom elicited by synthetic epitopes. Vaccine 2009, 27, 4201-4208. [CrossRef] [PubMed]

35. Dias-Lopes, C.; Guimarães, G.; Felicori, L.; Fernandes, P.; Emery, L.; Kalapothakis, E.; Nguyen, C.; Molina, F.; Granier, C.; Chávez-Olórtegui, C. A protective immune response against lethal, dermonecrotic and hemorrhagic effects of Loxosceles intermedia venom elicited by a 27-residue peptide. Toxicon 2010, 55, 481-487. [CrossRef]

36. Figueiredo, L.F.M.; Dias-Lopes, C.; Alvarenga, L.M.; Mendes, T.M.; Machado-de-Ávila, R.A.; McCormack, J.; Minozzo, J.C.; Kalapothakis, E.; Chávez-Olórtegui, C. Innovative immunization protocols using chimeric recombinant protein for the production of polyspecific loxoscelic antivenom in horses. Toxicon 2014, 86, 59-67. [CrossRef]

37. Lima S de, A.; Guerra-Duarte, C.; Costal-Oliveira, F.; Mendes, T.M.; Figueiredo, L.F.M.; Oliveira, D.; Machado de Avila, R.A.; Ferrer, V.P.; Trevisan-Silva, D.; Veiga, S.S.; et al. Recombinant protein containing B-cell epitopes of different Loxosceles spider toxins generates neutralizing antibodies in immunized rabbits. Front. Immunol. 2018, 9, 653. [CrossRef]

38. Safdari, Y.; Farajnia, S.; Asgharzadeh, M.; Khalili, M. Antibody humanization methods-A review and update. Biotechnol. Genet. Eng. Rev. 2013, 29, 175-186. [CrossRef]

39. Lebozec, K.; Jandrot-Perrus, M.; Avenard, G.; Favre-Bulle, O.; Billiald, P. Design, development and characterization of ACT017, a humanized Fab that blocks platelet's glycoprotein VI function without causing bleeding risks. MAbs 2017, 9, 945-958. [CrossRef]

40. Lebozec, K.; Jandrot-Perrus, M.; Avenard, G.; Favre-Bulle, O.; Billiald, P. Quality and cost assessment of a recombinant antibody fragment produced from mammalian, yeast and prokaryotic host cells: A case study prior to pharmaceutical development. N. Biotechnol. 2018, 44, 31-40. [CrossRef]

41. Dondelinger, M.; Filée, P.; Sauvage, E.; Quinting, B.; Muyldermans, S.; Galleni, M.; Vandevenne, M.S. Understanding the significance and implications of antibody numbering and antigen-binding surface/residue definition. Front. Immunol. 2018, 9, 2278. [CrossRef]

42. Waldmann, H. Human monoclonal antibodies: The benefits of humanization. Methods Mol. Biol. 2019, 1904, 1-10.

43. Doevendans, E.; Schellekens, H. Immunogenicity of innovative and biosimilar monoclonal antibodies. Antibodies 2019, 8, 21. [CrossRef]

44. Moussa, E.M.; Panchal, J.P.; Moorthy, B.S.; Blum, J.S.; Joubert, M.K.; Narhi, L.O.; Topp, E.M. Immunogenicity of therapeutic protein aggregates. J. Pharm. Sci. 2016, 105, 417-430. [CrossRef]

45. Van der Kant, R.; Karow-Zwick, A.R.; Van Durme, J.; Blech, M.; Gallardo, R.; Seeliger, D.; Aßfalg, K.; Baatsen, P.; Compernolle, G.; Gils, A.; et al. Prediction and reduction of the aggregation of monoclonal antibodies. J. Mol. Biol. 2017, 429, 1244-1261. [CrossRef]

46. Morgan, H.; Tseng, S.-Y.; Gallais, Y.; Leineweber, M.; Buchmann, P.; Riccardi, S.; Nabhan, M.; Lo, J.; Gani, Z.; Szely, N.; et al. Evaluation of in vitro assays to assess the modulation of dendritic cells functions by therapeutic antibodies and aggregates. Front. Immunol. 2019, 10, 601. [CrossRef] [PubMed]

47. Jerabek-Willemsen, M.; Wienken, C.J.; Braun, D.; Baaske, P.; Duhr, S. Molecular interaction studies using microscale thermophoresis. Assay Drug Dev. Technol. 2011, 9, 342-353. [CrossRef] [PubMed]

48. Coronado, M.A.; Ullah, A.; da Silva, L.S.; Chaves-Moreira, D.; Vuitika, L.; Chaim, O.M.; Veiga, S.S.; Chahine, J.; Murakami, M.T.; Arni, R.K. Structural insights into substrate binding of brown spider venom class II phospholipases, D. Curr. Protein Pept. Sci. 2015, 16, 768-774. [CrossRef] [PubMed] 
49. Lajoie, D.M.; Roberts, S.A.; Zobel-Thropp, P.A.; Delahaye, J.L.; Bandarian, V.; Binford, G.J.; Cordes, M.H.J. Variable substrate preference among phospholipase D toxins from Sicariid spiders. J. Biol. Chem. 2015, 290, 10994-11007. [CrossRef]

50. Dias-Lopes, C.; Neshich, I.A.P.; Neshich, G.; Ortega, J.M.; Granier, C.; Chávez-Olortegui, C.; Molina, F.; Felicori, L. Identification of new sphingomyelinases D in pathogenic fungi and other pathogenic organisms. PLOS ONE 2013, 8, e79240. [CrossRef]

51. de Giuseppe, P.O.; Ullah, A.; Silva, D.T.; Gremski, L.H.; Wille, A.C.M.; Chaves Moreira, D.; Ribeiro, A.S.; Chaim, O.M.; Murakami, M.T.; Veiga, S.S.; et al. Structure of a novel class II phospholipase D: Catalytic cleft is modified by a disulphide bridge. Biochem. Biophys. Res. Commun. 2011, 409, 622-627. [CrossRef]

52. Tambourgi, D.V.; Gonçalves-de-Andrade, R.M.; van den Berg, C.W. Loxoscelism: From basic research to the proposal of new therapies. Toxicon 2010, 56, 1113-1119. [CrossRef] [PubMed]

53. Felicori, L.; Araujo, S.C.; de Avila, R.A.M.; Sanchez, E.F.; Granier, C.; Kalapothakis, E.; Chávez-Olórtegui, C. Functional characterization and epitope analysis of a recombinant dermonecrotic protein from Loxosceles intermedia spider. Toxicon 2006, 48, 509-519. [CrossRef] [PubMed]

54. Mendes, T.M.; Oliveira, D.; Figueiredo, L.F.M.; Machado-de-Avila, R.A.; Duarte, C.G.; Dias-Lopes, C.; Guimarães, G.; Felicori, L.; Minozzo, J.C.; Chávez-Olortegui, C. Generation and characterization of a recombinant chimeric protein $(\mathrm{rCpLi})$ consisting of B-cell epitopes of a dermonecrotic protein from Loxosceles intermedia spider venom. Vaccine 2013, 31, 2749-2755. [CrossRef] [PubMed]

55. Gremski, L.H.; da Silveira, R.B.; Chaim, O.M.; Probst, C.M.; Ferrer, V.P.; Nowatzki, J.; Weinschutz, H.C.; Madeira, H.M.; Gremski, W.; Nader, H.B.; et al. A novel expression profile of the Loxosceles intermedia spider venomous gland revealed by transcriptome analysis. Mol. Biosyst. 2010, 6, 2403-2416. [CrossRef] [PubMed]

56. De Moura, J.; Felicori, L.; Moreau, V.; Guimarães, G.; Dias-Lopes, C.; Molina, L.; Alvarenga, L.M.; Fernandes, P.; Frézard, F.; Ribeiro, R.R.; et al. Protection against the toxic effects of Loxosceles intermedia spider venom elicited by mimotope peptides. Vaccine 2011, 29, 7992-8001. [CrossRef] [PubMed]

57. Laustsen, A.H.; María Gutiérrez, J.; Knudsen, C.; Johansen, K.H.; Bermúdez-Méndez, E.; Cerni, F.A.; Jürgensen, J.A.; Ledsgaard, L.; Martos-Esteban, A.; Øhlenschlæger, M.; et al. Pros and cons of different therapeutic antibody formats for recombinant antivenom development. Toxicon 2018, 146, 151-175. [CrossRef]

58. Engmark, M.; Andersen, M.R.; Laustsen, A.H.; Patel, J.; Sullivan, E.; de Masi, F.; Hansen, C.S.; Kringelum, J.V.; Lomonte, B.; Gutiérrez, J.M.; et al. High-throughput immuno-profiling of mamba (Dendroaspis) venom toxin epitopes using high-density peptide microarrays. Sci. Rep. 2016, 6, 36629. [CrossRef]

59. Engmark, M.; Lomonte, B.; Gutiérrez, J.M.; Laustsen, A.H.; De Masi, F.; Andersen, M.R.; Lund, O. Cross-recognition of a pit viper (Crotalinae) polyspecific antivenom explored through high-density peptide microarray epitope mapping. Plos Negl. Trop. Dis. 2017, 11, e0005768. [CrossRef]

60. Röthlisberger, D.; Honegger, A.; Plückthun, A. Domain interactions in the Fab fragment: A comparative evaluation of the single-chain Fv and Fab format engineered with variable domains of different stability. J. Mol. Biol. 2005, 347, 773-789. [CrossRef]

61. Chaves-Moreira, D.; Chaim, O.M.; Sade, Y.B.; Paludo, K.S.; Gremski, L.H.; Donatti, L.; de Moura, J.; Mangili, O.C.; Gremski, W.; da Silveira, R.B.; et al. Identification of a direct hemolytic effect dependent on the catalytic activity induced by phospholipase-D (dermonecrotic toxin) from brown spider venom. J. Cell Biochem. 2009, 107, 655-666. [CrossRef]

62. Tambourgi, D.V.; Paixão-Cavalcante, D.; Gonçalves de Andrade, R.M.; de Fernandes-Pedrosa, M.F.; Magnoli, F.C.; Morgan, B.P.; van den Berg, C.W. Loxosceles sphingomyelinase induces complement-dependent dermonecrosis, neutrophil infiltration, and endogenous gelatinase expression. J. Investig. Dermatol. 2005, 124, 725-731. [CrossRef] [PubMed]

63. Manzoni-de-Almeida, D.; Squaiella-Baptistão, C.C.; Lopes, P.H.; van den Berg, C.W.; Tambourgi, D.V. Loxosceles venom Sphingomyelinase D activates human blood leukocytes: Role of the complement system. Mol. Immunol. 2018, 94, 45-53. [CrossRef] [PubMed]

64. Quintero-Hernández, V.; Del Pozo-Yauner, L.; Pedraza-Escalona, M.; Juárez-González, V.R.; Alcántara-Recillas, I.; Possani, L.D.; Becerril, B. Evaluation of three different formats of a neutralizing single chain human antibody against toxin $\mathrm{Cn} 2$ : Neutralization capacity versus thermodynamic stability. Immunol. Lett. 2012, 143, 152-160. [CrossRef] [PubMed] 
65. Voors-Pette, C.; Lebozec, K.; Dogterom, P.; Jullien, L.; Billiald, P.; Ferlan, P.; Renaud, L.; Favre-Bulle, O.; Avenard, G.; Machacek, M.; et al. Safety and tolerability, pharmacokinetics, and pharmacodynamics of ACT017, an antiplatelet GPVI (glycoprotein VI) Fab: First-in-human healthy volunteer trial. ATVB 2019, 39, 956-964. [CrossRef] [PubMed]

66. Quintero-Hernández, V.; Juárez-González, V.R.; Ortíz-León, M.; Sánchez, R.; Possani, L.D.; Becerril, B. The change of the $\mathrm{scFv}$ into the Fab format improves the stability and in vivo toxin neutralization capacity of recombinant antibodies. Mol. Immunol. 2007, 44, 1307-1315. [CrossRef]

67. Lawrence, P.B.; Price, J.L. How PEGylation influences protein conformational stability. Curr. Opin. Chem. Biol. 2016, 34, 88-94. [CrossRef]

68. Appel, R.D.; Bairoch, A.; Hochstrasser, D.F. A new generation of information retrieval tools for biologists: The example of the ExPASy WWW server. Trends Biochem. Sci. 1994, 19, 258-260. [CrossRef]

69. Jiacomini, I.; Silva, S.K.; Aubrey, N.; Muzard, J.; Chavez-Olortegui, C.; De Moura, J.; Billiald, P.; Alvarenga, L.M. Immunodetection of the "brown" spider (Loxosceles intermedia) dermonecrotoxin with an scFv-alkaline phosphatase fusion protein. Immunol. Lett. 2016, 173, 1-6. [CrossRef]

70. Honegger, A.; Plückthun, A. Yet another numbering scheme for immunoglobulin variable domains: An automatic modeling and analysis tool. J. Mol. Biol. 2001, 309, 657-670. [CrossRef]

71. Abhinandan, K.R.; Martin, A.C.R. Analyzing the "degree of humanness" of antibody sequences. J. Mol. Biol. 2007, 369, 852-862. [CrossRef]

72. Muzard, J.; Adi-Bessalem, S.; Juste, M.; Laraba-Djebari, F.; Aubrey, N.; Billiald, P. Grafting of protein L-binding activity onto recombinant antibody fragments. Anal. Biochem. 2009, 388, 331-338. [CrossRef] [PubMed]

73. Ehrenmann, F.; Lefranc, M.-P. IMGT/DomainGapAlign: IMGT standardized analysis of amino acid sequences of variable, constant, and groove domains (IG, TR, MH, IgSF, MhSF). Cold Spring Harb. Protoc. 2011, 2011, 737-749. [CrossRef] [PubMed]

74. Ward, E.S.; Güssow, D.; Griffiths, A.D.; Jones, P.T.; Winter, G. Binding activities of a repertoire of single immunoglobulin variable domains secreted from Escherichia coli. Nature 1989, 341, 544-546. [CrossRef] [PubMed]

75. Devaux, C.; Moreau, E.; Goyffon, M.; Rochat, H.; Billiald, P. Construction and functional evaluation of a single-chain antibody fragment that neutralizes toxin AahI from the venom of the scorpion Androctonus australis hector. Eur. J. Biochem. 2001, 268, 694-702. [CrossRef] [PubMed]

76. Sali, A.; Overington, J.P. Derivation of rules for comparative protein modeling from a database of protein structure alignments. Protein Sci. 1994, 3, 1582-1596. [CrossRef]

77. Altschul, S.F.; Lipman, D.J. Protein database searches for multiple alignments. Proc. Natl. Acad. Sci. USA 1990, 87, 5509-5513. [CrossRef]

78. Luiz, M.; Pereira, S.; Prado, N.; Gonçalves, N.; Kayano, A.; Moreira-Dill, L.; Sobrinho, J.; Zanchi, F.; Fuly, A.; Fernandes, C.; et al. Camelid single-domain antibodies (VHHs) against crotoxin: A basis for developing modular building blocks for the enhancement of treatment or diagnosis of crotalic envenoming. Toxins 2018, 10, 142. [CrossRef]

79. Pettersen, E.F.; Goddard, T.D.; Huang, C.C.; Couch, G.S.; Greenblatt, D.M.; Meng, E.C.; Ferrin, T.E. UCSF Chimera-A visualization system for exploratory research and analysis. J. Comput. Chem. 2004, 25, 1605-1612. [CrossRef]

80. Kozakov, D.; Hall, D.R.; Xia, B.; Porter, K.A.; Padhorny, D.; Yueh, C.; Beglov, D.; Vajda, S. The ClusPro web server for protein-protein docking. Nat. Protoc. 2017, 12, 255-278. [CrossRef]

81. Brenke, R.; Hall, D.R.; Chuang, G.-Y.; Comeau, S.R.; Bohnuud, T.; Beglov, D.; Schueler-Furman, O.; Vajda, S.; Kozakov, D. Application of asymmetric statistical potentials to antibody-protein docking. Bioinformatics 2012, 28, 2608-2614. [CrossRef]

82. Laskowski, R.A.; Watson, J.D.; Thornton, J.M. Protein function prediction using local 3D templates. J. Mol. Biol. 2005, 351, 614-626. [CrossRef] [PubMed]

(C) 2020 by the authors. Licensee MDPI, Basel, Switzerland. This article is an open access article distributed under the terms and conditions of the Creative Commons Attribution (CC BY) license (http://creativecommons.org/licenses/by/4.0/). 